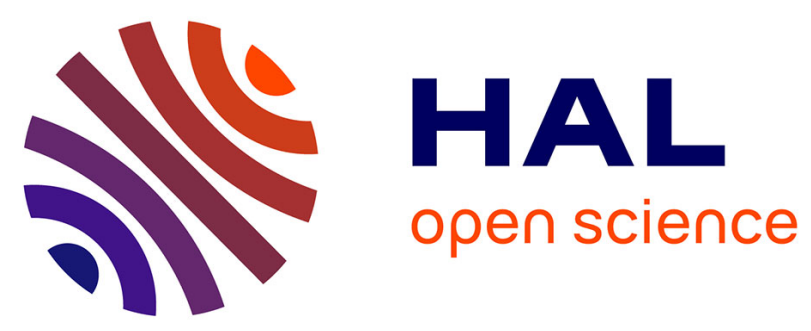

\title{
Naphthalimide-Based Dyes as Photoinitiators under Visible Light Irradiation and their Applications: Photocomposite Synthesis, 3D printing and Polymerization in Water
}

Mahmoud Rahal, Haifaa Mokbel, Bernadette Graff, Vincent Pertici, Didier

Gigmes, Joumana Toufaily, Tayssir Hamieh, Frédéric Dumur, Jacques Lalevée

\section{To cite this version:}

Mahmoud Rahal, Haifaa Mokbel, Bernadette Graff, Vincent Pertici, Didier Gigmes, et al.. Naphthalimide-Based Dyes as Photoinitiators under Visible Light Irradiation and their Applications: Photocomposite Synthesis, 3D printing and Polymerization in Water. ChemPhotoChem, 2021,5 (5), pp.476-490. 10.1002/cptc.202000306 . hal-03230339

\section{HAL Id: hal-03230339 https://hal.science/hal-03230339}

Submitted on 19 May 2021

HAL is a multi-disciplinary open access archive for the deposit and dissemination of scientific research documents, whether they are published or not. The documents may come from teaching and research institutions in France or abroad, or from public or private research centers.
L'archive ouverte pluridisciplinaire HAL, est destinée au dépôt et à la diffusion de documents scientifiques de niveau recherche, publiés ou non, émanant des établissements d'enseignement et de recherche français ou étrangers, des laboratoires publics ou privés. 
Naphthalimide-Based Dyes as Photoinitiators under Visible Light Irradiation and their Applications: Photocomposite Synthesis, 3D printing and Polymerization in Water

Mahmoud Rahal,[a, b, c] Haifaa Mokbel,[a, b] Bernadette Graff,[a, b] Vincent Pertici,[d]

Didier Gigmes,[d] Joumana Toufaily,[c] Tayssir Hamieh,[c, e] Frédéric Dumur, ${ }^{*}[d]$ and

Jacques Lalevée, *

1 Université de Haute-Alsace, CNRS, IS2M UMR 7361, F-68100 Mulhouse, France. mahmoud-rahal@ outlook.com (M.R); haifaa.mokbel@uha.fr (H.F); bernadette.graff@uha.fr (B.G).

2 Université de Strasbourg, Strasbourg, France.

3 Laboratory of Materials, Catalysis, Environment and Analytical Methods (MCEMA) and LEADDER Laboratory, Faculty of Sciences, Doctoral School of Sciences and Technology (EDST), Lebanese University, Beirut 6573-14, Lebanon; tayssir.hamieh@ul.edu.lb (T.H), Joumana.toufaily@ul.edu.lb (J.T).

4 Aix Marseille Univ, CNRS, ICR UMR 7273, F-13397 Marseille, France

5 SATIE-IFSTTAR, Université Gustave Eiffel, Campus de Marne-La-Vallée, 25, allée des Marronniers, F-78000 Versailles, France. tayssir.hamieh@ul.edu.lb (T.H).

* Corresponding authors: frederic.dumur@univ-amu.fr (FD); jacques.lalevee@ uha.fr (J. L)

\section{Abstract:}

In this work, six new fluorescent dyes derived from the Naphthalimide scaffold (Napht1 Napht6) were synthesized and used as high-performance photoinitiating systems (PISs) in two and three-component systems (combined with iodonium salt (Iod) and / or an electron donor amine (such as $N$-phenylglycine - NPG) for the radical photopolymerization of the acrylate and methacrylate monomers under visible light using a light-emitting diode (LED) at $405 \mathrm{~nm}$. In fact, these PISs showed high initiation efficiency with both a high final reactive function conversions and high polymerization rates. Interest of our study is to determine the effect of the different substituent (chromophoric group) on the naphthalimide function, concerning the efficiency of initiation of the free radical polymerization (FRP). In order to improve the mechanical properties of the obtained polymers, these derivatives were also tested for the photopolymerization of a mixture of acrylate / epoxy monomers (TA/EPOX); these latter properties were characterized by traction tests. To demonstrate the initiation efficiency of these dyes, several methods and characterization techniques were used, including steady state photolysis, real-time Fourier transform infrared spectroscopy (RT-FTIR), emission spectroscopy as well as cyclic voltammetry. In our study, these naphthalimides were used for the synthesis of photocomposites (one and multiple layers of glass fibres) using a UV@395 nm $\left(4 \mathrm{~W} / \mathrm{cm}^{2}\right)$ conveyor, as well as in the preparation of $3 \mathrm{D}$ printed polymers. Markedly, one of the 
naphthalimide (Napht-4) can be used as a new high-performance water soluble photoinitiator for photopolymerization in water and hydrogel synthesis.

Keywords: Naphthalimide, LED, 3D printing, Photocomposite, IPN, water soluble photoinitiator.

\section{Introduction}

Industrial technological developments during the last decades have been largely influenced by the ability to synthesize high performance materials that are essential for our daily life but also with the aim at developing environmentally friendly materials. Therefore, it was necessary to introduce light into the creation of these polymer-based materials in order to reduce the harmful effects of the other industrial synthesis processes. The term photopolymerization therefore designates the transformation of a liquid formulation into a solid material under irradiation [1,2], it is, therefore, a green technology since the reaction takes place at room temperature [3-8]. Photopolymers thus obtained are used in different fields such as coatings, dentistry, automotive, cosmetics, composites as well as 3D printing. Considering the harmfulness, the high energy consumption as well as the danger for the operator related to the use of UV lamps (e.g. Hg based), these irradiation setups are now more and more widely discarded in favor of light-emitting diodes (LEDs) [8-11], which can be inexpensive, durable, ecological, exhibit a low energy consumption and be safe for the operator.

The challenge is, therefore, to develop new molecules, whose absorption zones match the emission spectrum of visible LEDs (for example $405 \mathrm{~nm}$ LEDs) as well as to improve their photophysical and photochemical properties to act as high-performance photoinitiators (PI) for the FRP. Hence, the use of dyes based on Naphthalimide is investigated in this study. Indeed, these compounds are composed of an aromatic ring group connected to a phthalimide group and the electron delocalization resulting from the presence of the electron-withdrawing phthalimide group can give rise to an intramolecular charge transfer whose absorption band is located in the near UV or visible range $(350-500 \mathrm{~nm})$. These compounds are also characterized by high photoluminescence quantum yields so that these fluorescent organic compounds $[12,13]$ were ideal candidates for bioimaging [14] or the development of tumor-targeting drugdelivery systems (as DNA targeting, as cytotoxic agents, anticancer agent and as potential 
markers for cancers) [15]. Different naphthalimide derivatives have also been reported in the literature as high-performance PI for FRP and cationic polymerization (CP) of acrylate and epoxy functions, respectively [16-17]. Importance of using this type of molecule as PI is that they are easily modifiable by introducing chromophore groups onto the naphthalimide part [see ref.17]. As a result of this, absorption properties of these dyes can be easily modified as well as their photochemical and physical properties. This structural change can drastically affect the photoinitiation ability of the FRP reaction and therefore the final monomer conversions as well as the shape of the photopolymerization profiles.[18-26]

In this paper, six naphthalimides (Napht; Scheme 1) never reported in the literature were tested as photoinitiators for the photopolymerization of acrylates. These dyes showed good polymerization profiles when used in two and three-component photoinitiating systems (Napht/Iod or Napht/Iod/NPG). To provide a clear mechanistic picture, different characterization techniques were used in this work: UV-visible absorption spectroscopy and photolysis, emission spectroscopy, Fourier transform Infrared spectroscopy and cyclic voltammetry. Some applications in composites synthesis as well as in 3D printing are provided to highlight their high performances. Markedly, Napht-4 was also water-soluble and this compound could also be used for photopolymerization in water and for hydrogel synthesis.

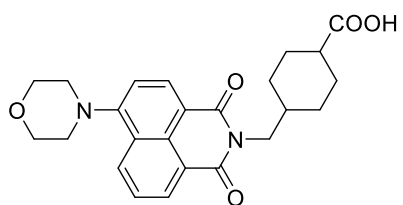

Napht-1

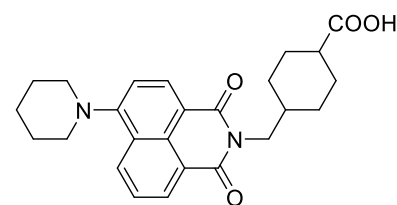

Napht-2

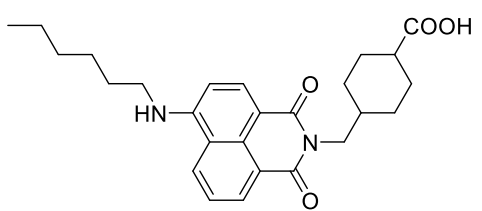

Napht-3

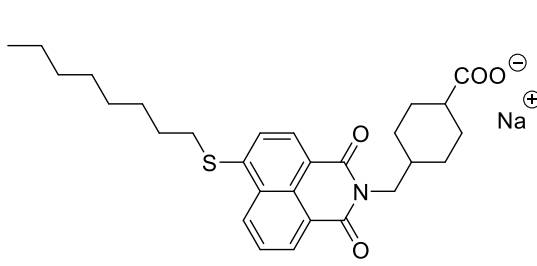

Napht-4

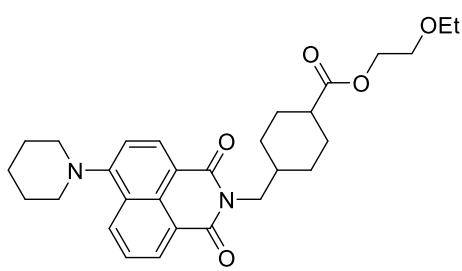

Napht-5

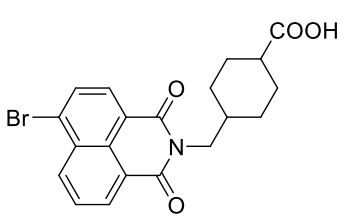

Napht-6

Scheme 1. New proposed Naphthalimides.

\section{Experimental part}

\subsection{Synthesis of the Naphthalimides}


All reagents and solvents were purchased from Aldrich or Alfa Aesar and used as received without further purification. Mass spectroscopy was performed by the Spectropole of AixMarseille University. ESI mass spectral analyses were recorded with a 3200 QTRAP (Applied Biosystems SCIEX) mass spectrometer. The HRMS mass spectral analysis was performed with a QStar Elite (Applied Biosystems SCIEX) mass spectrometer. Elemental analyses were recorded with a Thermo Finnigan EA 1112 elemental analysis apparatus driven by the Eager 300 software. ${ }^{1} \mathrm{H}$ and ${ }^{13} \mathrm{C}$ NMR spectra were determined at room temperature in $5 \mathrm{~mm}$ o.d. tubes on a Bruker Avance 400 spectrometer of the Spectropole: ${ }^{1} \mathrm{H}(400 \mathrm{MHz})$ and ${ }^{13} \mathrm{C}(100$ $\mathrm{MHz}$ ). The ${ }^{1} \mathrm{H}$ chemical shifts were referenced to the solvent peaks DMSO (2.49 ppm), $\mathrm{CDCl}_{3}$ (7.26 ppm) and the ${ }^{13} \mathrm{C}$ chemical shifts were referenced to the solvent peak DMSO (49.5 ppm), $\mathrm{CDCl}_{3}(77.0 \mathrm{ppm})$. All photoinitiators were prepared with analytical purity up to accepted standards for new organic compounds ( $>98 \%$ ) which was checked by high field NMR analysis.

Synthesis of 4-((6-morpholino-1,3-dioxo-1H-benzo[de]isoquinolin-2(3H)-yl)methyl)cyclohexane-1-carboxylic acid (Napht-1)

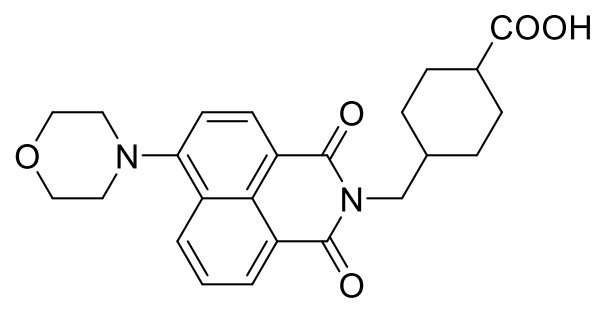

A mixture of 4-((6-bromo-1,3-dioxo-1H-benzo[de]isoquinolin-2(3H)-yl)methyl)cyclohexane1-carboxylic acid (1.02 g, $\left.2.45 \mathrm{mmol}, \mathrm{M}=416.27 \mathrm{~g} \cdot \mathrm{mol}^{-1}\right)$ and morpholine $(0.64 \mathrm{~g}, 0.64 \mathrm{~mL}$, 7.34 mmol, 3 eq., $\mathrm{M}=87.12$ g.mol $\left.{ }^{-1}, \mathrm{~d}=1.007\right)$ in DMF $(10 \mathrm{~mL})$ was stirred at reflux for $16 \mathrm{~h}$. After cooling to room temperature, the solvent was removed under reduced pressure using a rotary evaporator. The crude product was purified by column chromatography on silica gel $\left(\mathrm{CH}_{2} \mathrm{Cl}_{2} / \mathrm{MeOH}: 9 / 1\right)$ to provide an orange solid as the pure product $\left(900 \mathrm{mg}, 87 \%\right.$ yield). ${ }^{1} \mathrm{H}$ $\operatorname{NMR}\left(\mathrm{CDCl}_{3}\right) \delta: 8.55(\mathrm{~d}, J=7.1 \mathrm{~Hz}, 1 \mathrm{H}), 8.50(\mathrm{~d}, J=8.0 \mathrm{~Hz}, 1 \mathrm{H}), 8.40(\mathrm{~d}, J=8.4 \mathrm{~Hz}, 1 \mathrm{H})$, $7.68(\mathrm{t}, J=7.8 \mathrm{~Hz}, 1 \mathrm{H}), 7.21(\mathrm{~d}, J=8.0 \mathrm{~Hz}, 1 \mathrm{H}), 4.10-3.95(\mathrm{~m}, 6 \mathrm{H}), 3.25-3.25(\mathrm{~m}, 4 \mathrm{H}), 2.35-$ $2.20(\mathrm{~m}, 1 \mathrm{H}), 2.07-1.75(\mathrm{~m}, 5 \mathrm{H}), 1.45-1.25(\mathrm{~m}, 2 \mathrm{H}), 1.23-1.05(\mathrm{~m}, 2 \mathrm{H}), \mathrm{COOH}$ not detected; ${ }^{13} \mathrm{C} \mathrm{NMR}\left(\mathrm{CDCl}_{3}\right) \delta: 163.69,163.24,154.61,131.64,130.29,129.03,128.89,125.12,124.84$, 122.22, 116.06, 113.98, 65.94, 52.42, 44.55, 41.93, 35.10, 28.90, 27.29; HRMS (ESI MS) m/z: theor: 423.1914 found: $423.1918\left([\mathrm{M}+\mathrm{H}]^{+}\right.$detected $)$. 
Synthesis of 4-((1,3-dioxo-6-(piperidin-1-yl)-1H-benzo[de $]$ isoquinolin-2(3H)-yl)methyl) cyclohexane-1-carboxylic acid (Napht-2)

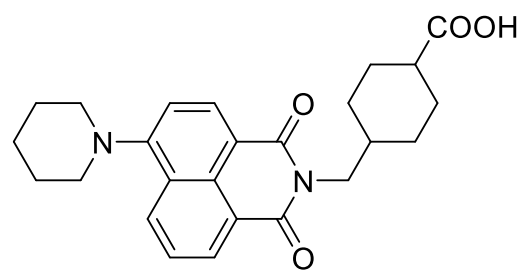

A mixture of 4-((6-bromo-1,3-dioxo-1H-benzo[de]isoquinolin-2(3H)-yl)methyl)cyclohexane1-carboxylic acid (1.14 g, $\left.2.74 \mathrm{mmol}, \mathrm{M}=416.27 \mathrm{~g} \cdot \mathrm{mol}^{-1}\right)$ and piperidine $(0.70 \mathrm{~g}, 0.81 \mathrm{~mL}$, $8.21 \mathrm{mmol}, 3$ eq., $\left.\mathrm{M}=85.15 \mathrm{~g} \cdot \mathrm{mol}^{-1}, \mathrm{~d}=0.861\right)$ in 2-ethoxyethanol $(10 \mathrm{~mL})$ was stirred at reflux for $16 \mathrm{~h}$. After cooling to room temperature, the solvent was removed under reduced pressure. The crude product was purified by column chromatography on silica gel $\left(\mathrm{CH}_{2} \mathrm{Cl}_{2} / \mathrm{MeOH}: 9 / 1\right)$ to provide an orange solid as the pure product $\left(1.66 \mathrm{~g}, 82 \%\right.$ yield). ${ }^{1} \mathrm{H}$ $\operatorname{NMR}\left(\mathrm{CDCl}_{3}\right) \delta: 8.55(\mathrm{~d}, J=5.8 \mathrm{~Hz}, 1 \mathrm{H}), 8.48(\mathrm{~d}, J=7.1 \mathrm{~Hz}, 1 \mathrm{H}), 8.38(\mathrm{~d}, J=7.1 \mathrm{~Hz}, 1 \mathrm{H})$, 7.66 (s, 1H), 7.17 (d, $J=7.3 \mathrm{~Hz}, 1 \mathrm{H}), 4.05$ (d, $J=4.2 \mathrm{~Hz}, 2 \mathrm{H}), 3.32-3.25(\mathrm{~m}, 4 \mathrm{H}), 3.05-3.00$ (m, 1H), 2.32-2.15 (m, 1H), $2.11-1.49(\mathrm{~m}, 11 \mathrm{H}), 1.45-1.12(\mathrm{~m}, 3 \mathrm{H}), \mathrm{COOH}$ not detected; Anal. Calc. for $\mathrm{C}_{25} \mathrm{H}_{28} \mathrm{~N}_{2} \mathrm{O}_{4}$ : C, 71.4; H, 6.7; O, 15.2; Found: C, 71.0; H, 6.2; O, $15.5 \%$; HRMS (ESI MS) m/z: theor: 421.2122 found: $421.2124\left([\mathrm{M}+\mathrm{H}]^{+}\right.$detected)

Synthesis of 4-((6-(hexylamino)-1,3-dioxo-1H-benzo[de]isoquinolin-2(3H)-yl)methyl) cyclohexane-1-carboxylic acid (Napht-3)

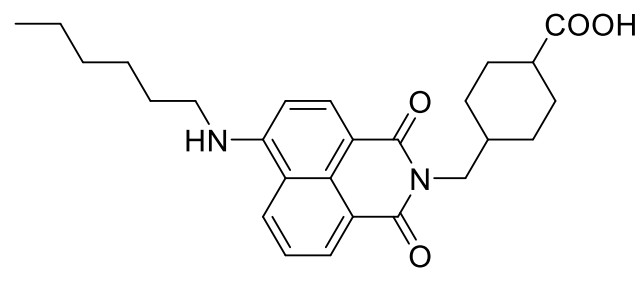

A mixture of 4-((6-bromo-1,3-dioxo-1H-benzo[de]isoquinolin-2(3H)-yl)methyl)cyclohexane1-carboxylic acid (0.60 g, $\left.1.44 \mathrm{mmol}, \mathrm{M}=416.27 \mathrm{~g} \cdot \mathrm{mol}^{-1}\right)$ and hexylamine $(0.44 \mathrm{~g}, 0.57 \mathrm{~mL}$, $4.32 \mathrm{mmol}, 3$ eq., $\left.\mathrm{M}=101.19 \mathrm{~g} \cdot \mathrm{mol}^{-1}, \mathrm{~d}=0.773\right)$ in 2-ethoxyethanol (5 mL) was stirred at reflux temperature for $16 \mathrm{~h}$. After cooling to room temperature, the solution was concentrated under reduced pressure until most of the solvent was removed. The residue was poured into the water $(30 \mathrm{~mL})$ and extracted with $\mathrm{CHCl}_{3}(3 \times 50 \mathrm{~mL})$. The combined organic layers were dried over $\mathrm{MgSO}_{4}$ and concentrated. The crude product was purified by column chromatography on 
silica gel $\left(\mathrm{CH}_{2} \mathrm{Cl}_{2} / \mathrm{MeOH}: 25 / 1\right.$ to $\left.10 / 1\right)$ to provide a yellow solid (478 $\mathrm{mg}, 76 \%$ yield). ${ }^{1} \mathrm{H}$ NMR $\left(\mathrm{CDCl}_{3}\right) \delta: 8.58(\mathrm{dd}, J=7.3,1.1 \mathrm{~Hz}, 1 \mathrm{H}), 8.54-8.47(\mathrm{~m}, 2 \mathrm{H}), 7.67(\mathrm{dt}, J=11.3,5.6$ $\mathrm{Hz}, 1 \mathrm{H}), 7.17(\mathrm{~d}, J=8.2 \mathrm{~Hz}, 1 \mathrm{H}), 4.20-4.11(\mathrm{~m}, 2 \mathrm{H}), 1.79-1.65(\mathrm{~m}, 6 \mathrm{H}), 1.47-1.23$ (m, $14 \mathrm{H}), 0.91$ (t, $8.6 \mathrm{~Hz}, 3 \mathrm{H}), \mathrm{COOH}$ and $\mathrm{NH}$ not detected; Anal. Calc. for $\mathrm{C}_{26} \mathrm{H}_{32} \mathrm{~N}_{2} \mathrm{O}_{4}$ : C, 71.5 ; H, 7.4; O, 14.7; Found: C, 71.2; H, 7.2; O, 14.5 \%; HRMS (ESI MS) m/z: theor: 437.2435 found: $437.2432\left([\mathrm{M}+\mathrm{H}]^{+}\right.$detected $)$

Synthesis of 4-((6-(octylthio)-1,3-dioxo-1H-benzo[de]isoquinolin-2(3H)-yl)methyl)cyclohexane-1-carboxylic acid (Napht-4-H)

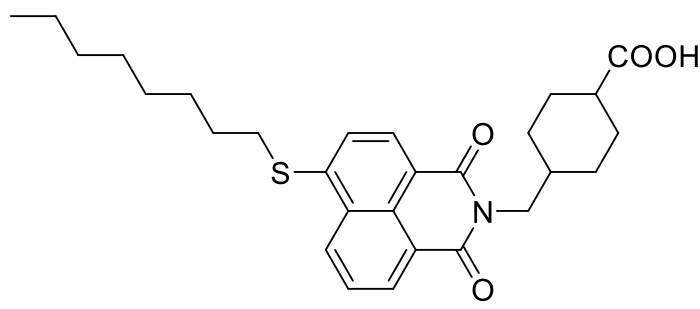

A mixture of 4-((6-bromo-1,3-dioxo-1H-benzo[de]isoquinolin-2(3H)-yl)methyl)cyclohexane1-carboxylic acid (0.60 g, $\left.1.44 \mathrm{mmol}, \mathrm{M}=416.27 \mathrm{~g} \cdot \mathrm{mol}^{-1}\right)$, octanethiol $(0.22 \mathrm{~g}, 0.26 \mathrm{~mL}, 1.51$ mmol, 1.05 eq., $\mathrm{M}=146.29$ g.mol $\left.{ }^{-1}, \mathrm{~d}=0.843\right)$ and $\mathrm{K}_{2} \mathrm{CO}_{3}(0.13 \mathrm{~g}, 0.94 \mathrm{mmol}, \mathrm{M}=138.2$ g.mol $\left.{ }^{-1}\right)$ in 2-ethoxyethanol $(5 \mathrm{~mL})$ was stirred at $50{ }^{\circ} \mathrm{C}$ for $16 \mathrm{~h}$. After cooling to room temperature, the solution was poured into water $(30 \mathrm{~mL})$ and extracted with $\mathrm{CHCl}_{3}(3 \times 50 \mathrm{~mL})$. The combined organic layers were dried over $\mathrm{MgSO}_{4}$ and concentrated. The crude product was purified on silica thin layer with $\mathrm{CH}_{2} \mathrm{Cl}_{2}$ and collected with ethanol. After evaporation of the solvent, the pure product was obtained as yellow solid (391 mg, $0.95 \mathrm{mmol}, 66 \%$ yield). ${ }^{1} \mathrm{H}$ $\operatorname{NMR}\left(\mathrm{CDCl}_{3}\right) \delta: 8.60(\mathrm{dd}, J=13.3,7.8 \mathrm{~Hz}, 2 \mathrm{H}), 8.47(\mathrm{~d}, J=7.9 \mathrm{~Hz}, 1 \mathrm{H}), 7.75(\mathrm{t}, J=7.9 \mathrm{~Hz}$, 1H), $7.54(\mathrm{~d}, J=7.9 \mathrm{~Hz}, 1 \mathrm{H}), 4.07(\mathrm{~d}, J=7.0 \mathrm{~Hz}, 2 \mathrm{H}), 3.16(\mathrm{~s}, 2 \mathrm{H}), 2.30$ (t, $J=12.0 \mathrm{~Hz}, 1 \mathrm{H})$, $2.02(\mathrm{~d}, J=11.5 \mathrm{~Hz}, 2 \mathrm{H}), 1.97-1.75(\mathrm{~m}, 4 \mathrm{H}), 1.51(\mathrm{dd}, J=14.5,7.4 \mathrm{~Hz}, 2 \mathrm{H}), 1.46-1.11(\mathrm{~m}$, $13 \mathrm{H}), 0.88$ (t, $8.6 \mathrm{~Hz}, 3 \mathrm{H}), \mathrm{COOH}$ not detected; Anal. Calc. for $\mathrm{C}_{28} \mathrm{H}_{35} \mathrm{NO}_{4} \mathrm{~S}: \mathrm{C}, 69.8 ; \mathrm{H}, 7.3$; O, 13.3; Found: C, 70.0; H, 7.2; O, $13.5 \%$; HRMS (ESI MS) m/z: theor: 482.2360 found: $482.2365\left([\mathrm{M}+\mathrm{H}]^{+}\right.$detected $)$ 
Synthesis of sodium 4-((6-(octylthio)-1,3-dioxo-1H-benzo[de $]$ isoquinolin-2(3H)yl)methyl)cyclohexane-1-carboxylate (Napht-4)

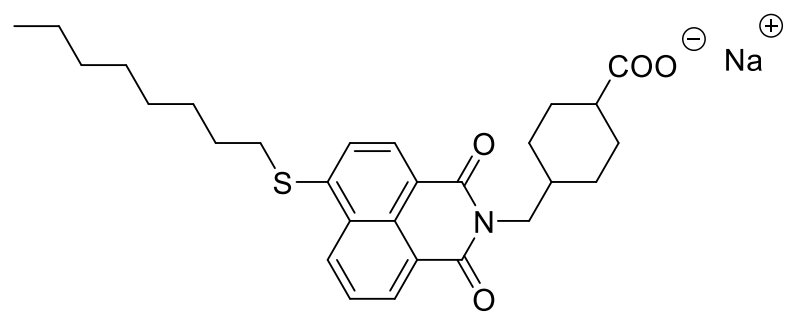

4-((6-(Octylthio)-1,3-dioxo-1H-benzo[de]isoquinolin-2(3H)-yl)methyl)cyclohexane-1-carboxylic acid ( $1 \mathrm{~g}, 2.08 \mathrm{mmol}, \mathrm{M}=481.65 \mathrm{~g} / \mathrm{mol})$ was solubilized in THF $(50 \mathrm{~mL})$ and aq. $\mathrm{NaOH}$ solution $(30 \%, 2 \mathrm{~mL})$ was added to the mixture. The solution was stirred under reflux for $3 \mathrm{~h}$. After cooling, THF and part of water were removed under reduced pressure. A precipitate formed. It was filtered off, washed several times with pentane and dried under vacuum (963 mg, 92\% yield). ${ }^{1} \mathrm{H}$ NMR $\left(\mathrm{D}_{2} \mathrm{O}\right) \delta: 7.95-7.89$ (brs, $\left.1 \mathrm{H}\right), 7.70-7.62$ (brs, $\left.1 \mathrm{H}\right), 7.58-7.50$ (brs, 1H), 7.23-7.15 (brs, 1H), 6.85-6.77 (brs, 1H), 3.65-3.50 (brs, 2H), 2.85-2.65 (brs, 2H), 2.152.03 (brs, 1H), 1.95-1.80 (m, 2H), 1.75-1.50 (m, 4H), 1.48-1.11 (m, 15H), $0.92(\mathrm{t}, 8.6 \mathrm{~Hz}, 3 \mathrm{H})$; Anal. Calc. for $\mathrm{C}_{28} \mathrm{H}_{34} \mathrm{NNaO}_{4} \mathrm{~S}$ : C, 66.8; H, 6.8; O, 12.7; Found: C, 66.2; H, 6.4; O, $12.8 \%$; HRMS (ESI MS) m/z: theor: 482.2360 found: $482.2358\left([\mathrm{M}+\mathrm{H}]^{+}\right.$detected)

Synthesis of 2-ethoxyethyl 4-((1,3-dioxo-6-(piperidin-1-yl)-1H-benzo[de]isoquinolin-2(3H)yl)methyl)cyclohexane-1-carboxylate (Napht-5)

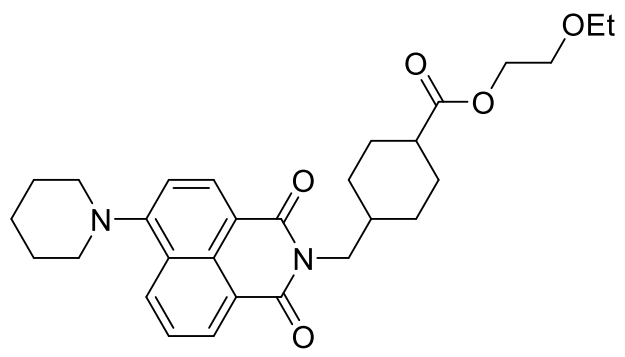

This compound was identified as a side-product formed during the synthesis of Napht-2. ${ }^{1} \mathrm{H}$ $\operatorname{NMR}\left(\mathrm{CDCl}_{3}\right) \delta: 8.57(\mathrm{dd}, J=7.3,1.0 \mathrm{~Hz}, 1 \mathrm{H}), 8.49(\mathrm{~d}, J=8.1 \mathrm{~Hz}, 1 \mathrm{H}), 8.41(\mathrm{dd}, J=8.4,1.0$ Hz, 1H), $7.72-7.64(\mathrm{~m}, 1 \mathrm{H}), 7.19$ (d, $J=8.1 \mathrm{~Hz}, 1 \mathrm{H}), 4.07$ (d, $J=6.9 \mathrm{~Hz}, 2 \mathrm{H}), 3.77-3.67$ (m, 4H), $3.59-3.48(\mathrm{~m}, 6 \mathrm{H}), 3.28-3.20(\mathrm{~m}, 2 \mathrm{H}), 2.35-1.69(\mathrm{~m}, 12 \mathrm{H}), 1.40(\mathrm{ddd}, J=26.0$, 13.1, 2.6 Hz, 2H), 1.23 (dd, $J=13.2,6.3 \mathrm{~Hz}, 3 \mathrm{H}$ ); Anal. Calc. for $\mathrm{C}_{29} \mathrm{H}_{36} \mathrm{~N}_{2} \mathrm{O}_{5}$ : C, 70.7; H, 7.4; O, 16.2; Found: C, 70.5; H, 7.4; O, $16.5 \%$; HRMS (ESI MS) m/z: theor: 493.2697 found: $493.2695\left([\mathrm{M}+\mathrm{H}]^{+}\right.$detected $)$ 
Synthesis of 4-((6-bromo-1,3-dioxo-1H-benzo[de]isoquinolin-2(3H)-yl)methyl)cyclohexane1-carboxylic acid (Napht-6)

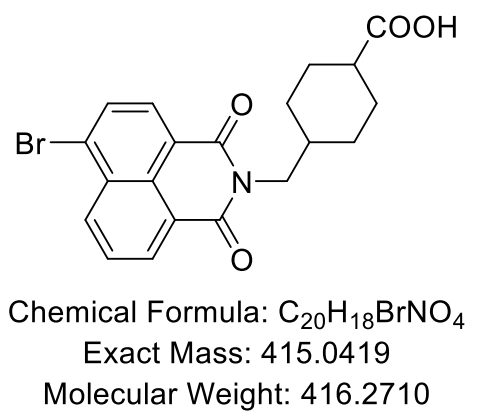

A mixture of 4-bromo-1,8-naphthalic anhydride $(6.0 \mathrm{~g}, 21.65 \mathrm{mmol})$ and trans-4(aminomethyl)cyclohexanecarboxylic acid (3.74 g, $23.82 \mathrm{mmol}, 1.1$ eq.) in DMF (70 mL) was stirred at reflux temperature for $4 \mathrm{~h}$. The reaction mixture was cooled to room temperature. The solvent was removed under reduced pressure. The residue was poured into ice cooled water and stirred for $15 \mathrm{~min}$. An orange precipitate formed. It was filtered off, rinsed several times with cold water and dried under vacuum $(7.93 \mathrm{~g}, 88 \%$ yield $) .{ }^{1} \mathrm{H} \mathrm{NMR}\left(\mathrm{CDCl}_{3}\right) \delta: 8.66(\mathrm{dd}, J=7.3$, $1.1 \mathrm{~Hz}, 1 \mathrm{H}), 8.58(\mathrm{dd}, J=8.5,1.1 \mathrm{~Hz}, 1 \mathrm{H}), 8.41(\mathrm{~d}, J=7.9 \mathrm{~Hz}, 1 \mathrm{H}), 8.05(\mathrm{~d}, J=7.9 \mathrm{~Hz}, 1 \mathrm{H})$, $7.85(\mathrm{dd}, J=8.5,7.3 \mathrm{~Hz}, 1 \mathrm{H}), 4.07$ (d, $J=7.1 \mathrm{~Hz}, 2 \mathrm{H}), 2.29(\mathrm{tt}, J=12.1,3.5 \mathrm{~Hz}, 1 \mathrm{H}), 2.09-$ $1.77(\mathrm{~m}, 5 \mathrm{H}), 1.40(\mathrm{ddd}, J=25.3,13.1,2.9 \mathrm{~Hz}, 2 \mathrm{H}), 1.28-1.11(\mathrm{~m}, 2 \mathrm{H}), \mathrm{COOH}$ not detected; Anal. Calc. for $\mathrm{C}_{20} \mathrm{H}_{18} \mathrm{BrNO}_{4}$ : C, 57.7; H, 4.4; O, 15.4; Found: C, 57.2; H, 4.2; O, $15.8 \%$; HRMS (ESI MS) m/z: theor: 416.0492 found: $416.0496\left([\mathrm{M}+\mathrm{H}]^{+}\right.$detected $)$

\subsection{Other chemical compounds}

All the other chemicals (Scheme 2) were selected with the highest purity available and used as received. Di-tert-butyl-diphenyl iodonium hexafluorophosphate (Iod) and ethyl 4(dimethylamino)benzoate (EDB) were obtained from Lambson Ltd (UK). (3,4 Epoxycyclohexane)methyl 3,4-epoxycyclohexylcarboxylate (EPOX; Uvacure 1500), trimethylolpropane triacrylate (TMPTA), di(trimethylolpropane) tetraacrylate (TA), Mix-MA, $N$-Phenylglycine (NPG) were obtained from Allnex or Sigma Aldrich. TMPTA, TA, Mix-MA and EPOX were selected as benchmark monomers for the radical and cationic polymerizations, respectively. 


\section{Additives}<smiles>CC(C)(C)c1ccc([I-](c2ccc([PH3+])cc2)c2ccc(C(C)(C)C)cc2)cc1</smiles>

lod<smiles>O=C(O)CNc1ccccc1</smiles>

NPG<smiles>CCOC(=O)c1ccc(N(C)C)cc1</smiles>

EDB<smiles>Cc1ccc(N(C)C)cc1</smiles>

4NNTMTA

\section{Monomers}<smiles>C=CC(=O)OCC(CC)(COC(=O)C=C)COC(=O)C=C</smiles>

TMPTA<smiles>O=C(OCC1CCC2OC2C1)C1CCC2OC2C1</smiles>

EPOX<smiles>C=CC(=O)OCC(CC)(COCC(CC)(COC(=O)C=C)COC(=O)C=C)COC(=O)C=C</smiles>

TA

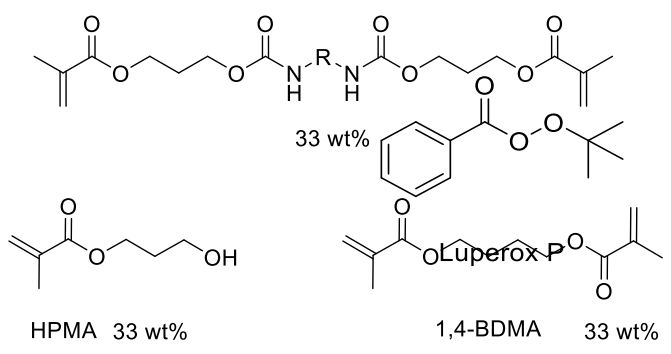

Mix-MA

Scheme 2. Other used chemical compounds used in this work.

\subsection{Irradiation sources}

The different sources of irradiation used in this work (polymerization of the photocurable samples, photolysis experiments and photocomposites synthesis) were the following: (1) LED@ 375nm with an incident light intensity at the sample surface $\mathrm{I}_{0}=40 \mathrm{~mW} \cdot \mathrm{cm}^{-2}$; (2) LED@ $405 \mathrm{~nm}$ with $\mathrm{I}_{0}=110 \mathrm{~mW} . \mathrm{cm}^{-2}$, (3) LED conveyor @395nm with $\mathrm{I}_{0}=4 \mathrm{~W} / \mathrm{cm}^{2}$.

\subsection{Free radical photopolymerization (FRP) and Interpenetrating polymer network} (IPN) synthesis

FRP experiments were carried out using two and three-component photoinitiating systems based on: Napht/Iod $(0.1 \% / 1 \%$ w/w) and Napht/Iod/NPG $(0.1 \% / 1 \% / 1 \%$ w/w/w). Conversely, IPNs were only prepared using two-components PISs: Napht/Iod $(0.1 \% / 1 \%$ w/w). Higher percentages in PI were also studied (0.2\% in Napht) in this last case. The percentages 
of the components in the photoinitiation system were calculated from the global monomer content.

Two types of samples were studied: i) thick samples: where the resin containing the reactive system was deposited in a circular mold (thickness $=1.4 \mathrm{~mm}$ ) in which the polymerization of the acrylate or epoxy functions could take place or ii) thin samples: where the photopolymerizable resin is sandwiched between 2 polypropylene films (thickness $=25 \mu \mathrm{m}$ ) for the FRP and the IPN synthesis. In fact, the polymerization rate (Rp) as well as the final reactive functions conversion (FC) of FRP (TA and TMPTA) were monitored by following by evolution of the $\mathrm{C}=\mathrm{C}$ peak located at $6160 \mathrm{~cm}^{-1}$ and $1630 \mathrm{~cm}^{-1}$ for the thick and thin samples respectively. For the epoxy functions, peaks at $3744 \mathrm{~cm}^{-1}$ and $790 \mathrm{~cm}^{-1}$ were selected for the thick and thin samples respectively. RT-FTIR experiments were carried out using a JASCO 6600 FTIR spectrometer.

\subsection{Redox potentials}

Redox potentials for Naphthalimide derivatives ( $E_{o x}$ and $\left.E_{r e d}\right)$ were determined by cyclic voltammetry using tetrabutylammonium hexafluorophosphate as the supporting electrolyte (potentials vs. Saturated Calomel Electrode - SCE) in acetonitrile. The free energy change $\left(\Delta \mathrm{G}_{\mathrm{et}}\right)$ for an electron transfer reaction was calculated from eq.1 [27], where $\mathrm{E}_{\mathrm{ox}}, \mathrm{E}_{\mathrm{red}}, \mathrm{E}^{*}$, and $\mathrm{C}$ represent the oxidation potential of the electron donor, the reduction potential of the electron acceptor, the excited state energy level (determined from luminescence experiments) and the coulombic term for the initially formed ion pair, respectively. Here, $\mathrm{C}$ is neglected as usually done for polar solvents.

$$
\Delta \mathrm{G}_{\mathrm{et}}=\mathrm{E}_{\mathrm{ox}}-\mathrm{E}_{\mathrm{red}}-\mathrm{E}^{*}+\mathrm{C}
$$

\subsection{UV-Visible absorption and photolysis experiments}

The UV-visible absorption spectra, the molar extinction coefficients and the steady state photolysis experiments of Naphthalimide derivatives (in acetonitrile) have been studied using a JASCO V730 UV-visible spectrometer.

\subsection{Fluorescence experiments}

Fluorescence properties of the different compounds in chloroform were investigated using a JASCO FP-6200 spectrofluorimeter. The fluorescence quenching of ${ }^{1} \mathrm{Napht}$ by Iod were investigated from the classical Stern-Volmer treatment [1] $\left(\mathrm{I}_{0} / \mathrm{I}=1+\mathrm{kq} \tau_{0}[\operatorname{Iod}]\right.$, where $\mathrm{I}_{0}$ and 
I stand for the fluorescent intensity of Naphthalimide in the absence and the presence of Iod, respectively; $\tau_{0}$ stands for the lifetime of Naphthalimide in the absence of Iod).

\subsection{Computational Procedure}

Molecular orbital calculations were carried out with the Gaussian 03 suite of programs [28,29]. Electronic absorption spectra for the different compounds were calculated with the time-dependent density functional theory at the MPW1PW91-FC/6-31G* level of theory on the relaxed geometries calculated at the UB3LYP/6-31G* level of theory. The triplet state energy levels were calculated at this level of theory.

\subsection{Near-UV conveyor for photocomposite synthesis}

For the synthesis of photocomposites, a Dymax-UV conveyor is used. Firstly, the photopolymerizable resin has been deposited on the glass fibres $(50 \% / 50 \% \mathrm{w} / \mathrm{w})$ and then the samples were irradiated using a LED conveyor at $395 \mathrm{~nm}\left(4 \mathrm{~W} / \mathrm{cm}^{2}\right)$. The distance between the belt and the LED was fixed at $15 \mathrm{~mm}$, and the belt speed was fixed at $2 \mathrm{~m} / \mathrm{min}$.

\subsection{D printing experiments}

3D printing experiments were carried out using a computer-controlled diode laser at 405 $\mathrm{nm}($ spot size $=50 \mu \mathrm{m})$, these experiments were performed under air. 3D patterns were analyzed using a numerical optical microscope (DSX-HRSU from OLYMPUS Corporation) [22].

\subsection{Dynanometer experiments}

A Dynamometer INSTRON 4505 modernized Zwick (speed $=10 \mathrm{~mm} \cdot \mathrm{min}^{-1}$ ) has been used to measure the shear stress (MPa) of material as a function of the elongation (mm). The materials were prepared in a silicone mold where the formulation was deposited and irradiated using an LED projector @395nm $\left(0.3 \mathrm{~W} / \mathrm{cm}^{2}\right)$.

\section{Results and discussion}

Influence of the different groups attached to the Naphthalimide core on the photochemical and photophysical properties as well as the chemical mechanisms have been investigated in details.

\subsection{Light absorption properties}


Absorption spectra as well as the molar extinction coefficients of the naphthalimide derivatives in acetonitrile are depicted in Figure 1 (See also Table 1). In fact, these compounds are characterized by a main band and a high absorption capacity (e.g.: Napht-2: $\varepsilon=11300 \mathrm{M}^{-}$ ${ }^{1} \mathrm{~cm}^{-1}$ at $405 \mathrm{~nm}$; Napht-3: $\varepsilon=10860 \mathrm{M}^{-1} \mathrm{~cm}^{-1}$ at $405 \mathrm{~nm}$ ) in the near UV as well as in the visible range (350-500 $\mathrm{nm})$. These absorption properties provide an excellent overlap with the emission spectra of the near UV or visible LEDs used in this work (LED @ 375nm, 395nm and 405nm).

UV-visible absorption spectra as well as the molar extinction coefficients are drastically impacted by the substituent linked to the naphthalimide scaffold. Notably, introduction of an electron donating group resulting in a bathochromic shift of the absorption spectra whereas introduction of an electron withdrawing group produced an hypsochromic shift of the intramolecular charge transfer band. The electron-donating effect of these substituents is presented as follows by ascending order: Napht-3 $>$ Napht- 2 and $5>$ Napht-6 $>$ Napht- $1>$ Napht-4.

Optimized geometries as well as the frontier orbitals (Highest Occupied Molecular Orbital - HOMO - and Lowest Unoccupied Molecular Orbital - LUMO) are shown in Figure 2. The electron donating group strongly participates to the HOMO orbital (except Napht-4), while the LUMO one is localized onto the naphthalimide core, thus ensuring a partial charge character 
for this $\pi-\pi *$ transition. In fact, the alkyl group present in Napht-3 and Napht-4 also gives a fast solubility of these molecules in the photopolymerizable resin (see below).

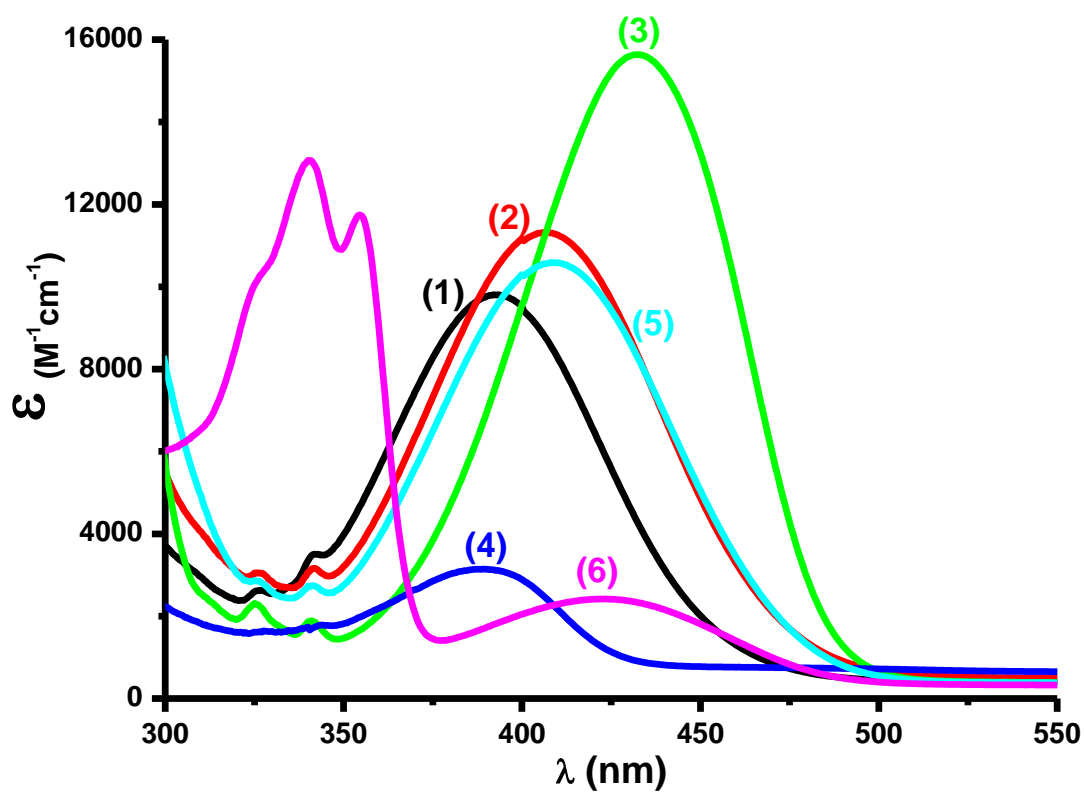

Figure 1. UV-visible absorption spectra of the investigated compounds in ACN: (1) Napht-1, (2) Napht2, (3) Napht-3, (4) Napht-4, (5) Napht-5 and (6) Napht-6.

Table 1. Light absorption properties of Naphthalimide compounds at $405 \mathrm{~nm}$ and at $\lambda_{\max }$.

\begin{tabular}{|c|c|c|c|}
\hline & $\lambda_{\max }$ & $\begin{array}{c}\mathcal{E}_{\max } \\
\left(M^{-1} \mathrm{~cm}^{-1}\right)\end{array}$ & $\begin{array}{c}\mathcal{E}_{@ 405 \mathrm{~nm}} \\
\left(\mathrm{M}^{-1} \mathrm{~cm}^{-1}\right)\end{array}$ \\
\hline Napht-1 & 392 & 9810 & 8960 \\
\hline Napht-2 & 406 & 11320 & 11300 \\
\hline Napht-3 & 432 & 15640 & 10860 \\
\hline Napht-4 & 389 & 3140 & 2570 \\
\hline Napht-5 & 408 & 10590 & 10510 \\
\hline Napht-6 & 423 & 2420 & 2180 \\
\hline
\end{tabular}




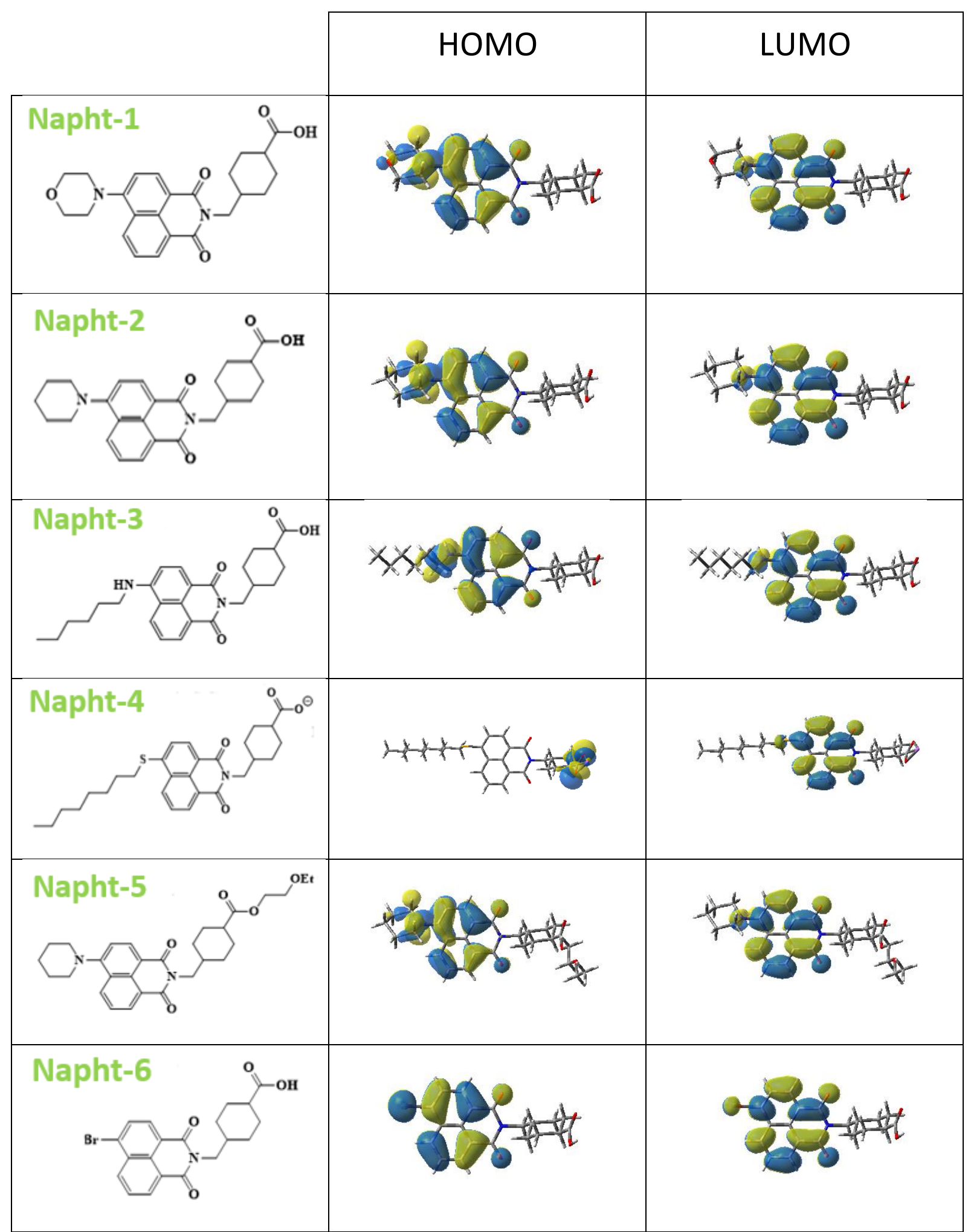

Figure 2. HOMO and LUMO frontier orbitals for the different investigated compounds at the UB3LYP/6- 31G* level. 


\subsection{Free Radical Photopolymerization (FRP)}

\subsubsection{Photopolymerization of methacrylate monomers (Mix-MA)}

Since the different compounds showed a significant absorption in the near UV as well as in the visible range, the dyes were tested as photoinitiators for the FRP of methacrylate-based monomers.

In fact, these compounds showed very good photopolymerization profiles in thick samples and the results are depicted in Figure 3 (and see also Table 2). The use of a two-component PIS (Napht/Iod) enabled to get interesting photopolymerization profiles in terms of polymerization rates but the three-component PISs obtained by the introduction of an amine into the photosensitive resin showed a greater efficiency i.e. a better final methacrylate function conversion (FC) and a higher polymerization rate (e.g. FC $=68 \%$ for Napht-6/Iod $(0.2 \% / 1 \%$ w/w) vs. $86 \%$ for Napht-6/Iod/NPG $(0.2 \% / 1 \% / 1 \%$ w/w/w $))$. Presence of the Naphthalimidebased photosensitizer is crucial for the global performance i.e. Napht/Iod/NPG being better PIS than Iod/NPG e.g. Figure 3, curve 12 vs. curve 13.

It is important to note that the polymerization profiles for Mix-MA were lower than those obtained with TMPTA or TA (see below). This may be due to the low viscosity of Mix-MA which causes a higher oxygen inhibition.

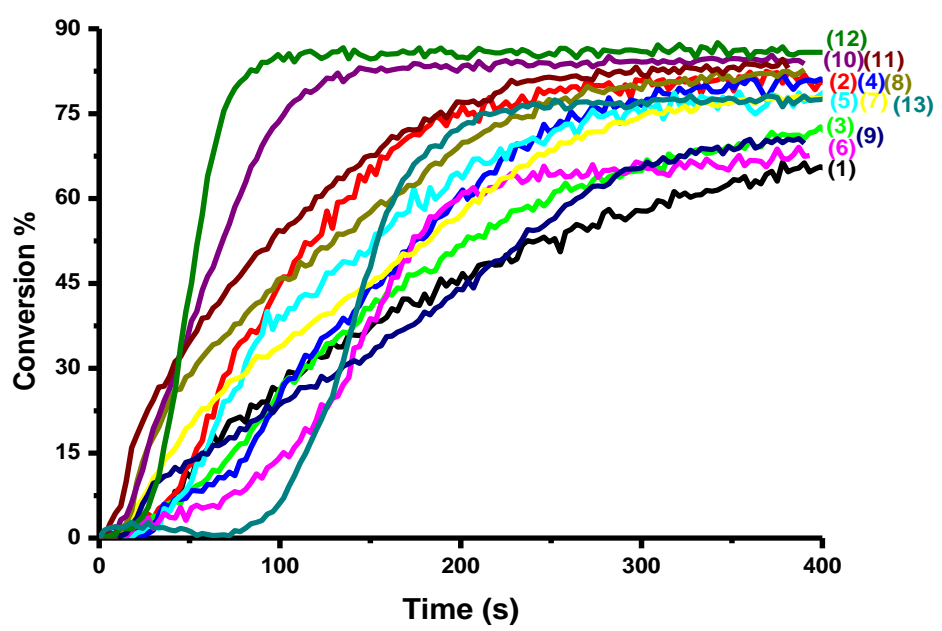

Figure 3. Photopolymerization profiles (methacrylate function conversion vs. irradiation time) for MixMA (thickness $=1.4 \mathrm{~mm}$ ) upon exposure to the LED @ $405 \mathrm{~nm}$ in the presence of the two-component photoinitiating systems: Napht/Iod $(0.1 \%$ / 1\% w/w) : (1) Napht-1, (2) Napht-2, (3) Napht-3, (4) Napht4, (5) Napht-5, (6) Napht-6 (0.2\%/1\% w/w); and three-component PIS Napht/Iod/NPG $(0.1 \% / 1 \% / 1 \%$ w/w/w) :(7) Napht-1, (8) Napht-2, (9) Napht-3, (10) Napht-4, (11) Napht-5, (12) Napht-6 (0.2\%/1\%/1\% $\mathrm{w} / \mathrm{w} / \mathrm{w})$ and (13) Iod/NPG $(1 \% / 1 \% \mathrm{w} / \mathrm{w})$. Irradiation starts at $\mathrm{t}=10 \mathrm{~s}$. 


\subsubsection{Photopolymerization of acrylate monomers (TA and TMPTA)}

Typical acrylate function conversion-time profiles are given in Figure 4, and the final acrylate function conversions (FC) are gathered in Table 2. The FRP of TMPTA and TA was investigated in both thick $(1.4 \mathrm{~mm})$ and thin $(25 \mu \mathrm{m})$ samples using two and three component PISs. The FRP of acrylates in the presence of the two-component Napht/Iod $(0.1 \% / 1 \% \mathrm{w} / \mathrm{w})$ and the three-component Napht/Iod/NPG $(0.1 \% / 1 \% / 1 \% \mathrm{w} / \mathrm{w} / \mathrm{w})$ photoinitiating systems is very efficient compared to Napht, Iod or NPG considered alone which shows no polymerization of the acrylate functions. This latter result unambiguously confirms the role of the naphthalimide dyes as photoinitiators.

The obtained results clearly show that Napht-2 leads to a very efficient polymerization, compared to the other structures, in terms of FC and Rp for the FRP of TA, e.g. FC $=85 \%$ for Napht-2 vs 68\%, 62\%, 65\%, 81\% and 64\% for Napht-1,3,4,5 and Napht-6 (Figure 4B curves 1-6). These results can be explained by a more efficient photo-oxidation interaction between Napht-2 and Iod. The efficiency of the FRP (i.e. for the FC) using a LED@405 nm clearly follows the trend Napht-2 $>$ Napht-5 $>$ Napht-1 $>$ Napht-4 $>$ Napht-6 $>$ Napht-3. In fact, an increase of the PI concentration induced a decrease in the final conversion of the acrylate functions, this may be due to an inner filter effect which prevents the penetration of the incident light into the photosensitive resin (see Table 2).

On the other hand, an improvement in the performance of FRP was observed using NPG as a third component in the photosensitizable resin (Napht/Iod/NPG $(0.1 \% / 1 \% / 1 \% \mathrm{w} / \mathrm{w} / \mathrm{w})$. In fact, the Iod/NPG $(1 \% / 1 \% \mathrm{w} / \mathrm{w})$ couple showed a quite efficient polymerization in the FRP of the acrylate functions ( $\mathrm{FC}=79 \%$; Figure 4B curve 13). It has to be noticed that Iod alone or NPG alone cannot induce a polymerization, this may be due to the formation of a charge transfer complex [Iod-NPG] $]_{\mathrm{CTC}}$ that can be activated under visible light irradiation. The addition of PI to the Iod/NPG couple effectively improved the polymerization profile, e.g. $\mathrm{FC}=90 \%$ for Napht-1/Iod/NPG $(0.1 \% / 1 \% / 1 \%$ w/w/w vs. $68 \%$ for Napht-1/Iod $(0.1 \% / 1 \%$ w/w) (Figure 4B, curve 1 vs curve 7 ). 

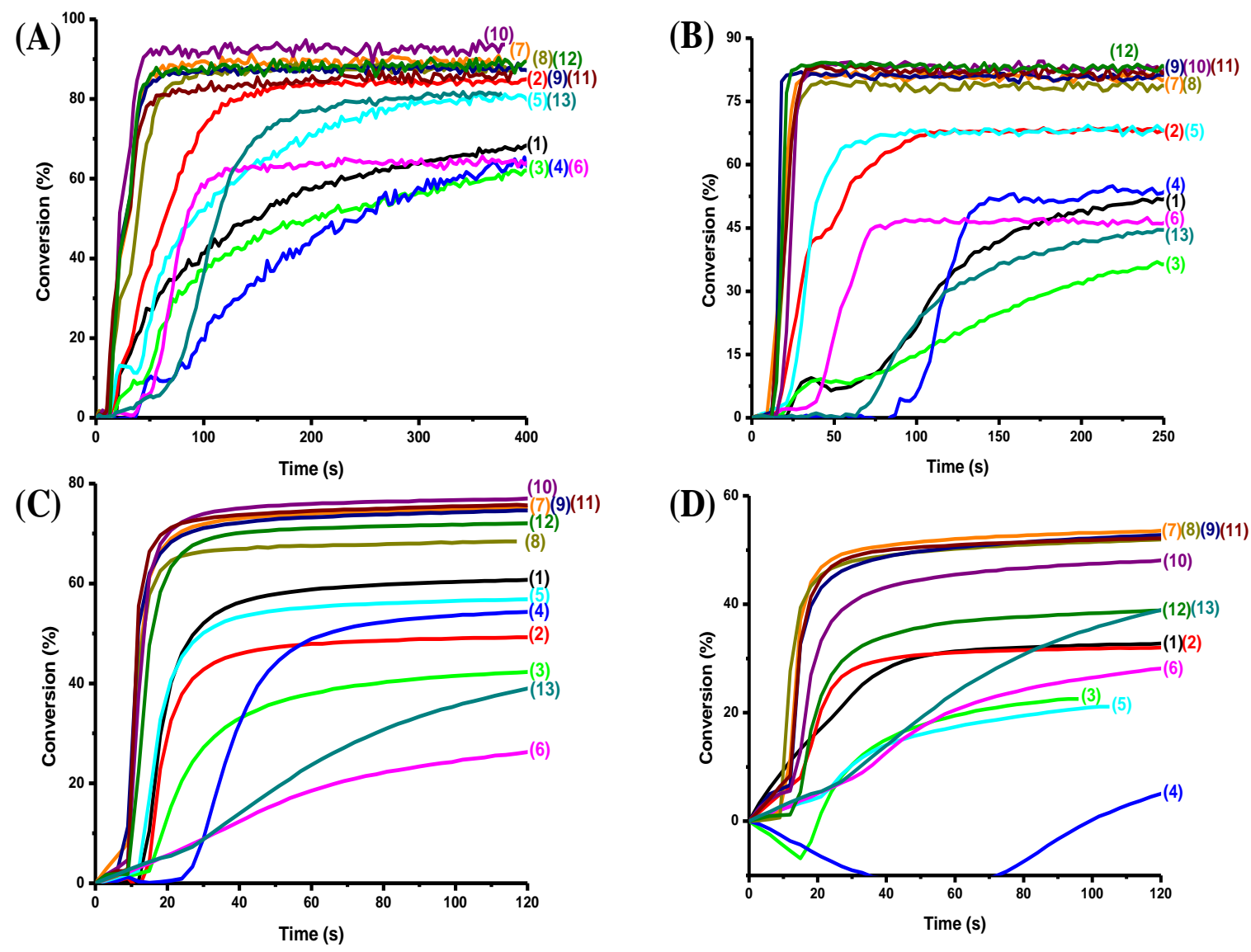

Figure 4. Polymerization profiles (acrylate function conversion vs. irradiation time): (A) for TA; thick samples $(1.4 \mathrm{~mm}),(\mathbf{B})$ for TA ; Thin samples $(25 \mu \mathrm{m})$; (C) for TMPTA; thick samples $(1.4 \mathrm{~mm})$ and (D) for TMPTA; thin samples $(25 \mu \mathrm{m})$ upon exposure to the LED @ $405 \mathrm{~nm}$ in the presence of the twocomponent photoinitiating systems Napht/Iod (0.1\%/1\% w/w): (1) Napht-1, (2) Napht-2, (3) Napht-3, (4) Napht-4, (5) Napht-5, (6) Napht-6, and Three-component photoinitiating systems Napht/Iod/NPG $(0.1 \% / 1 \% / 1 \%$ w/w/w) : (7) Napht-1, (8) Napht-2, (9) Napht-3, (10) Napht-4, (11) Napht-5, (12) Napht6 and (13) Iod/NPG (1\%/1\% w/w). Irradiation starts at $\mathrm{t}=10 \mathrm{~s}$.

Table 2. Final reactive functions conversion (FC\%) for different monomers and different PISs upon visible light irradiation using a LED @ $405 \mathrm{~nm}$ (400 s of irradiation and thickness=1.4 mm).

\begin{tabular}{|c|c|c|c|c|c|c|}
\hline \multicolumn{7}{|c|}{ Thick samples } \\
\hline & \multicolumn{3}{|c|}{$\begin{array}{c}\text { Two component PISs } \\
\text { Napht//Iod }(0.1 \%-0.2 \% / 1 \% \text { w/w }) \\
\end{array}$} & \multicolumn{3}{|c|}{$\begin{array}{c}\text { Three component PISs } \\
\text { Napht/Iod/NPG }(0.1 \% / 1 \% / 1 \% \text { w/w/w })\end{array}$} \\
\hline & TA & TMPTA & Mix-MA & TA & TMPTA & Mix-MA \\
\hline Napht-1 & $\begin{array}{l}68 \%^{a} \\
50 \%^{b}\end{array}$ & $\begin{array}{l}53 \%^{a} \\
61 \%\end{array}$ & $66 \%^{a}$ & $90 \%$ & $81 \%$ & $78 \%$ \\
\hline Napht-2 & $\begin{array}{l}85 \%^{a} \\
67 \%^{b}\end{array}$ & $\begin{array}{l}70 \%^{a} \\
58 \%^{b}\end{array}$ & $82 \%^{a}$ & $89 \%$ & $79 \%$ & $83 \%$ \\
\hline
\end{tabular}




\begin{tabular}{|c|c|c|c|c|c|c|}
\hline Napht-3 & $\begin{array}{l}62 \%^{a} \\
55 \%^{b}\end{array}$ & $\begin{array}{l}43 \%^{a} \\
44 \%^{b}\end{array}$ & $73 \%^{a}$ & $88 \%$ & $81 \%$ & $71 \%$ \\
\hline Napht-4 & $\begin{array}{l}65 \%^{a} \\
74 \%^{b}\end{array}$ & $\begin{array}{l}56 \%^{a} \\
51 \%^{b}\end{array}$ & $82 \%^{a}$ & $94 \%$ & $84 \%$ & $85 \%$ \\
\hline Napht-5 & $\begin{array}{l}81 \%^{a} \\
59 \%^{b}\end{array}$ & $\begin{array}{l}70 \%^{a} \\
60 \%^{b}\end{array}$ & $79 \%^{a}$ & $87 \%$ & $82 \%$ & $85 \%$ \\
\hline Napht-6 & $\begin{array}{l}64 \%^{a} \\
74 \%^{b}\end{array}$ & $\begin{array}{l}47 \%^{a} \\
54 \%^{b}\end{array}$ & $69 \%$ & $90 \%$ & $83 \%$ & $86 \%$ \\
\hline
\end{tabular}

a: Napht/Iod $(0.1 \% / 1 \% \mathrm{w} / \mathrm{w})$

b: Napht/Iod $(0.2 \% / 1 \% \mathrm{w} / \mathrm{w})$

Table 3. Final reactive functions conversion (FC\%) for different monomers and different PISs upon visible light irradiation using a LED @ 405nm (400 s of irradiation; and thickness= $25 \mu \mathrm{m}$ in laminate).

\begin{tabular}{|c|c|c|c|c|}
\hline \multicolumn{5}{|c|}{ Thin samples } \\
\hline & \multicolumn{2}{|c|}{$\begin{array}{c}\text { Two component PISs } \\
\text { Napht/Iod }(0.1 \%-0.2 \% / 1 \% \text { w/w }) \\
\end{array}$} & \multicolumn{2}{|c|}{$\begin{array}{c}\text { Three component PISs } \\
\text { Napht/Iod/NPG }(0.1 \% / 1 \% / 1 \% \text { w/w/w })\end{array}$} \\
\hline & TA & TMPTA & TA & TMPTA \\
\hline Napht-1 & $\begin{array}{l}61 \%^{a} \\
71 \%^{b}\end{array}$ & $33 \%^{a}$ & $75 \%$ & $54 \%$ \\
\hline Napht-2 & $\begin{array}{l}50 \%^{a} \\
61 \%^{b}\end{array}$ & $\begin{array}{l}32 \%^{a} \\
37 \%^{b}\end{array}$ & $68 \%$ & $52 \%$ \\
\hline Napht-3 & $\begin{array}{l}43 \%^{a} \\
63 \%^{b}\end{array}$ & $\begin{array}{l}23 \%^{a} \\
39 \%^{b}\end{array}$ & $75 \%$ & 53 \\
\hline Napht-4 & $\begin{array}{l}55 \%^{a} \\
52 \%^{b}\end{array}$ & $\begin{array}{l}\text { n.p\% }{ }^{a} \\
40 \%\end{array}$ & $77 \%$ & $49 \%$ \\
\hline Napht-5 & $\begin{array}{l}57 \%^{a} \\
59 \%^{b}\end{array}$ & $\begin{array}{l}21 \%^{a} \\
49 \%^{b}\end{array}$ & $76 \%$ & $53 \%$ \\
\hline Napht-6 & $\begin{array}{l}29 \%^{a} \\
51 \%^{b}\end{array}$ & $\begin{array}{l}30 \%^{a} \\
\text { n.p } \%^{b}\end{array}$ & $72 \%$ & $39 \%$ \\
\hline
\end{tabular}

a: Napht/Iod $(0.1 \% / 1 \% \mathrm{w} / \mathrm{w})$

b: Napht/Iod $(0.2 \% / 1 \% \mathrm{w} / \mathrm{w})$

\subsubsection{IPN synthesis}

An interpenetrating polymer network (IPN) is a polymer based on two different monomers (more precisely, in our work, TA and EPOX) polymerizing in different conditions. Thus, two 
polymer networks are simultaneously formed, but they are not linked together (just tangled). The aim of such type of process is to improve the mechanical properties by widening the glass transition regions of IPN materials relative to their components. The results obtained with different percentage of monomers are summarized in Table 4. The experiments showed that the $70 \% / 30 \%$ ratio in TA / EPOX monomers was the best composition in terms of the conversion rates of both functionalities (acrylates and epoxides).

Table 4. Final monomer conversions (FC\%) of acrylate and epoxide functions using the PISs based on Napht/Iod/NPG $(0.1 \% / 1 \% / 1 \%$ w/w/w) upon visible light irradiation using a LED @405nm (1000 s of irradiation; thickness $=1.4 \mathrm{~mm}$ ).

\begin{tabular}{|c|c|c|c|}
\hline \multirow{2}{*}{} & \multicolumn{3}{|c|}{ TA/ EPOX (w/w) } \\
\cline { 2 - 4 } & $\mathbf{5 0 \% / 5 0 \%}$ & $\mathbf{7 0 \% / 3 0 \%}$ & $\mathbf{1 0 0 \% / 0 \%}$ \\
\hline Napht-1 & $93 \% / 29 \%$ & $91 \% / 43 \%$ & $68 \%$ \\
\hline Napht-2 & $95 \% / 0 \%$ & $80 \% / 15 \%$ & $85 \%$ \\
\hline Napht-3 & $93 \% / 40 \%$ & $81 \% / 32 \%$ & $62 \%$ \\
\hline Napht-4 & $78 \% / 0 \%$ & $87 \% / 0 \%$ & $65 \%$ \\
\hline Napht-5 & $94 \% / 37 \%$ & $93 \% / 45 \%$ & $80 \%$ \\
\hline Napht-6 & $87 \% / 29 \%$ & $87 \% / 21 \%$ & $64 \%$ \\
\hline
\end{tabular}

\subsection{D-printing experiments using Napht/Iod/Amine systems}

The new Naphthalimide derivatives have been tested in direct laser write experiments, using a laser diode at $405 \mathrm{~nm}$. Some examples of the polymers obtained under air using different PISs such as Napht/Iod/NPG (0.04\%/0.4\%/0.4\% w/w/w) or Napht/Iod/NPG $(0.04 \% / 0.4 \% / 0.4 \%$ $\mathrm{w} / \mathrm{w} / \mathrm{w})$ in TA are presented in the Figure 5. Some of them have been obtained with a great thickness (going up to $1900 \mu \mathrm{m})$, a great spatial resolution $(50 \mu \mathrm{m})$ and in a very short irradiation time ( $\sim 2$ minutes). Interestingly, these colored 3D patterns showed a very strong green fluorescence when characterized by digital light microscopy. An example of IPN 3D printed pattern is also given in Figure 5E. 
(A)
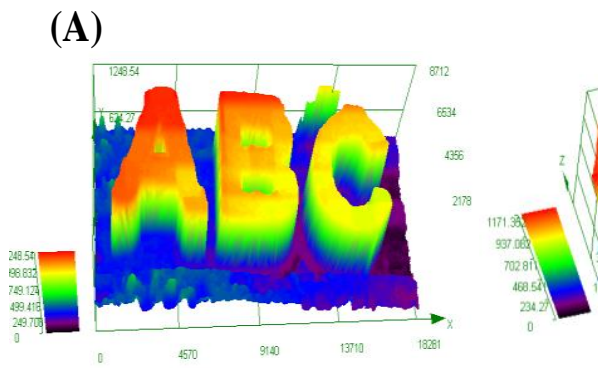

(D)

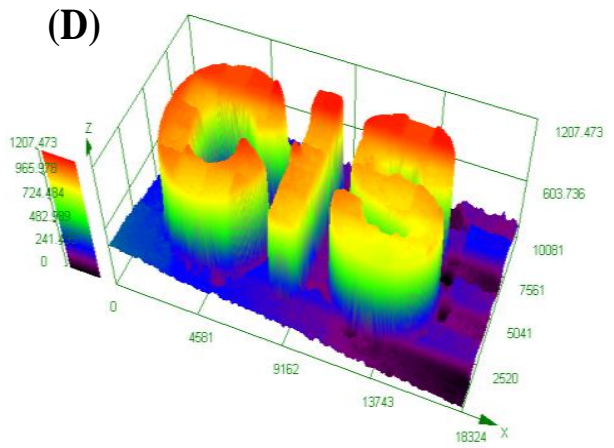

(B)

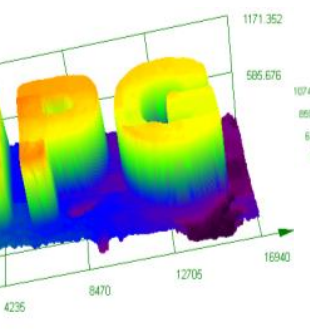

(C)

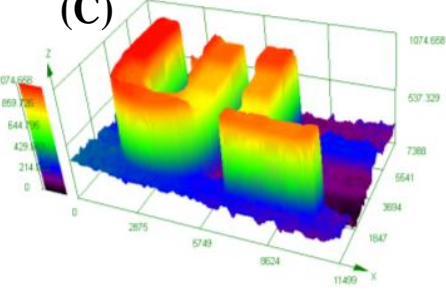

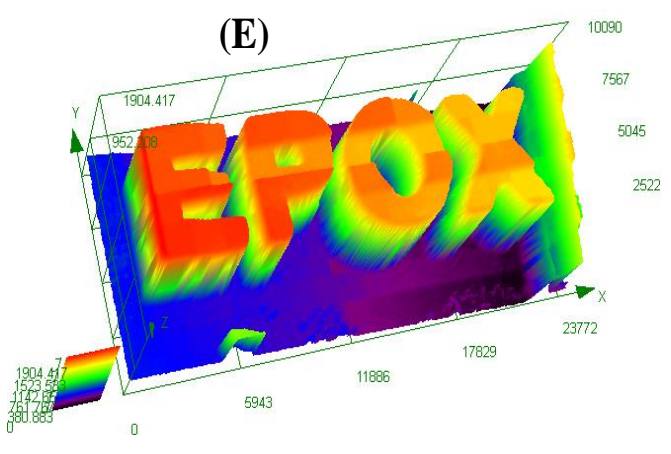

Figure 5. Free Radical photopolymerization (FRP) (using TA as benchmark monomer) for direct laser write experiments @ $405 \mathrm{~nm}$ : Characterization of 3D patterns by numerical optical microscopy: (A) Napht-1/Iod/4NNTMA $(0.04 \% / 0.4 \% / 0.042 \%)$ in TA, (B) Napht-2/Iod/NPG $(0.04 \% / 0.4 \% / 0.4 \% \mathrm{w} / \mathrm{w} / \mathrm{w})$ in TA, (C) Napht-6/Iod/NPG $(0.08 \% / 0.4 \% / 0.4 \% \mathrm{w} / \mathrm{w} / \mathrm{w})$ in TA, (D) Napht-3/Iod/NPG $(0.05 \% / 0.5 \% / 0.5 \% \mathrm{w} / \mathrm{w} / \mathrm{w})$ in TA and (E) Napht-3/Iod/NPG $(0.05 \% / 0.5 \% / 0.5 \% \mathrm{w} / \mathrm{w} / \mathrm{w})$ in TA/EPOX $(50 \% / 50 \%)$

\subsection{Photocomposites synthesis using a LED conveyor}

During the last decades and until today, the production of composites materials represents a very dynamic market, since it is estimated at 90.6 billion dollars in 2019, the world market should reach more than 131.6 billion in 2024 (with an average annual growth rate of $7.7 \%$ ) [30]. This very important production is based on the very interesting mechanical properties of these new materials (lighter, chemically inert, with improved thermal and mechanical resistance ...).

In this work, naphthalimide-based photoinitiators have shown high efficiency in FRP using the three-component PISs. Therefore, these PISs were used for the manufacture of photocomposites based on glass fibres. The interest of using these materials as a matrix is that they have very important properties (e.g. impact resistance ...) as well as they are widely used in different fields, such as transport, buildings, infrastructure and industrial equipment. First of all, the photocomposites materials were prepared by impregnation of glass fibres (in 1 or 3 
layers) with an acrylic resin (50\% glass fibres / 50\% acrylic resin) and irradiated upon a LED@395nm. Remarkably, a very fast curing was observed where the surface and the bottom are tack-free (thickness $=2 \mathrm{~mm}$ ) after one pass only using different PISs in TA, but this is not the case for a greater thickness (three layers of glass fibres $\sim 6 \mathrm{~mm}$ ) where the bottom was tackfree after 13 passes using Napht-3/Iod/NPG $(0.1 \% / 1 \% / 1 \% \mathrm{w} / \mathrm{w} / \mathrm{w})$, and it's not the case for a blend of monomers (TA and EPOX) where the surface and the bottom are tack-free after one and 40 passes, respectively. The curing results obtained are gathered in Figure 6.

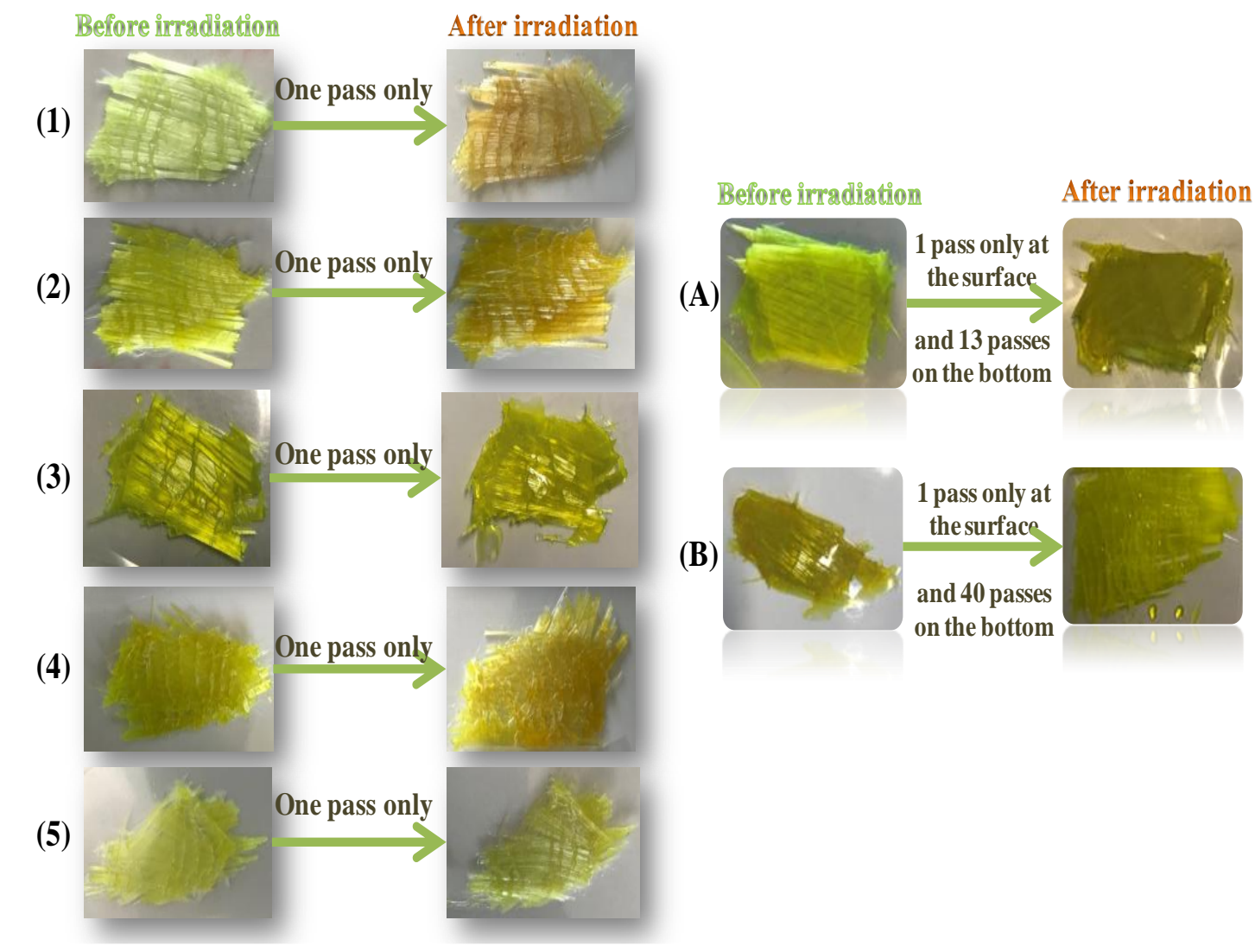

Figure 6. Photocomposites synthesis using FRP in the presence of glass fibres/ resin $50 \% / 50 \% \mathrm{w} / \mathrm{w}$ (Thickness =2 mm for one layer), using LED@395 nm and the Belt Speed was fixed at 2m/min: (1) Napht-1/Iod/NPG $(0.1 \% / 1 \% / 1 \% \mathrm{w} / \mathrm{w} / \mathrm{w})$, (2) Napht-2/Iod/NPG $(0.1 \% / 1 \% / 1 \% \mathrm{w} / \mathrm{w} / \mathrm{w})$, (3)Napht3/Iod/NPG $(0.1 \% / 1 \% / 1 \% \mathrm{w} / \mathrm{w} / \mathrm{w})$, (4) Napht-4/Iod/NPG $(0.1 \% / 1 \% / 1 \% \mathrm{w} / \mathrm{w} / \mathrm{w})$ and (5) Napht$5 / \mathrm{Iod} / \mathrm{NPG}(0.1 \% / 1 \% / 1 \% \mathrm{w} / \mathrm{w} / \mathrm{w})$ in TA. (A) and (B) are photocomposites produced upon the near-UV irradiation @395nm in the presence of glass fibres/resin 50\%/50\% w/w (thickness 6mm for 3 layers) for Napht-3/Iod/NPG $(0.1 \% / 1 \% 1 \% \mathrm{w} / \mathrm{w} / \mathrm{w})$ in TA and Napht3/Iod/NPG $(0.1 \% / 1 \% / 1 \% \mathrm{w} / \mathrm{w} / \mathrm{w})$ in Ebec40/EPOX (50\%/50\%). 


\subsection{Traction results}

The traction results of the materials obtained are shown in the Figure 7. In fact, these data confirmed the advantage of developing IPN materials in order to improve of the mechanical properties of the materials compared to those determined for polymers composed of only one type of monomer.

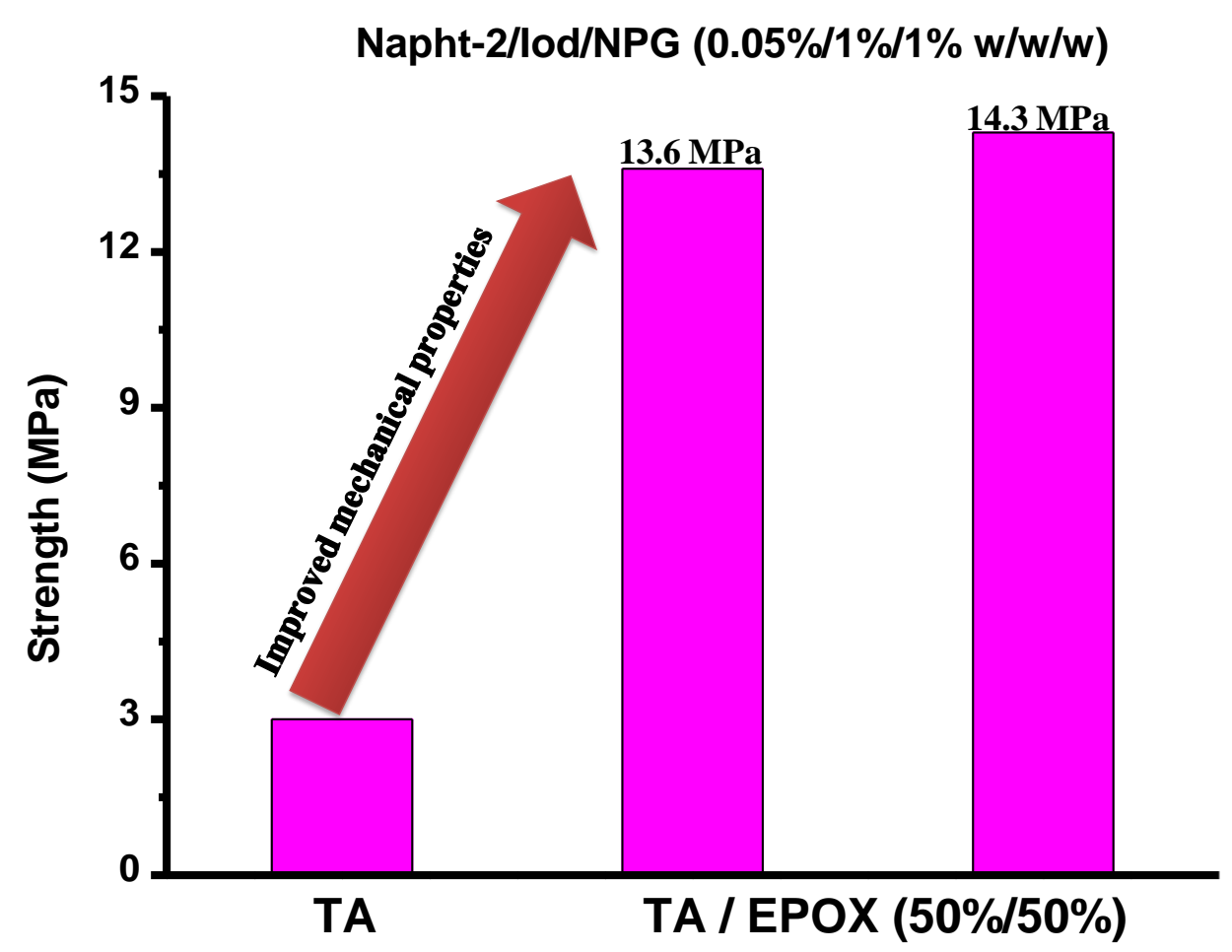

Figure 7. Traction results with the initiating system Napht-2/Iod/NPG $(0.05 \% / 1 \% / 1 \% \mathrm{w} / \mathrm{w} / \mathrm{w})$ for polymerized TA vs. TA/EPOX (50\%/50\%).

\subsection{Hydrogel synthesis using Napht-4/ Triethanolamine $(0.1 \% / 1 \%$ w/w $)$, Photopolymerization in water.}

Interestingly, Napht-4 was also water soluble and this compound could be advantageously used for photopolymerization in water and the preparation of hydrogels. Markedly, using the Napht-4/Triethanolamine system $(0.1 \% / 1 \% \mathrm{w} / \mathrm{w})$ in polyethylene glycol diacrylate/water blend (SR610 from Sartomer Europe), hydrogels could be easily obtained by irradiation of the formulation using a LED @ 405nm (Figure 8).

It is important to note that the UV-visible spectrum of Napht-4 in water showed a hyperchromic effect $\left(\varepsilon \sim 7000 \mathrm{M}^{-1} \mathrm{~cm}^{-1}\right.$ in water vs. $2570 \mathrm{M}^{-1} \mathrm{~cm}^{-1}$ in $\left.\mathrm{ACN}\right)$ compared to that obtained in ACN (Figure 9). 


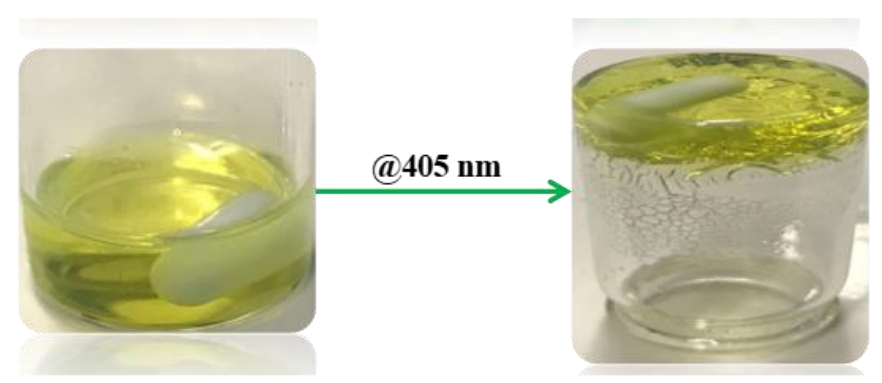

Figure 8. Hydrogels obtained before and after irradiation @ 405nm using Napht-4/Triethanolamine system $(0.1 \% / 1 \% \mathrm{w} / \mathrm{w})$ in polyethylene glycol diacrylate/water blend.

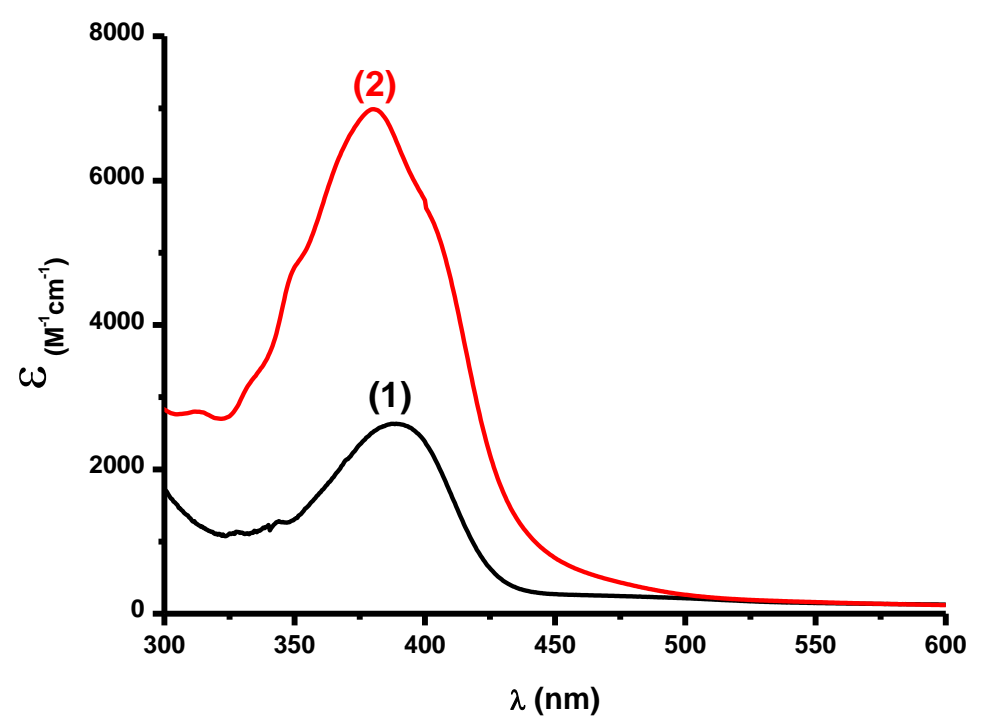

Figure 9. Absorption spectra of Napht-4 in: (1) ACN and (2) water.

\section{Discussion}

Photochemical and photophysical properties of the investigated Naphthalimides are now discussed in this part.

\section{1. steady state photolysis}

Steady state photolysis of the different Naphthalimides in acetonitrile and upon irradiation with LED@375nm have been carried out. Photolyses of Napht-2 alone, Napht-2/Iod and Napht2/NPG are reported in Figure 10. Firstly, photolysis of the Napht-2/Iod couple is faster than that of Napth-2 alone which does not show any obvious photolysis upon irradiation@375nm. Therefore, Napht-2 alone is photostable (Figure 10A). The appearance of a new peak during the irradiation of the Napht-2/Iod couple, as well as the decrease of the Napht-2 absorption evidences a strong interaction between the PI and Iod by an electron transfer process which 
results in the photolysis of the PI and the generation of a photoproduct observed between 475$550 \mathrm{~nm}$. Actually, the photolysis of Napht- 2 in the presence of the Iod/NPG couple $\left(10^{-2} \mathrm{M}\right)$ is very slow (Figure 10C) i.e. much less important than that observed with Iod alone (Figure 10D curve 2 and 3), clearly showing that Napht-2 is regenerated in the three-component system.
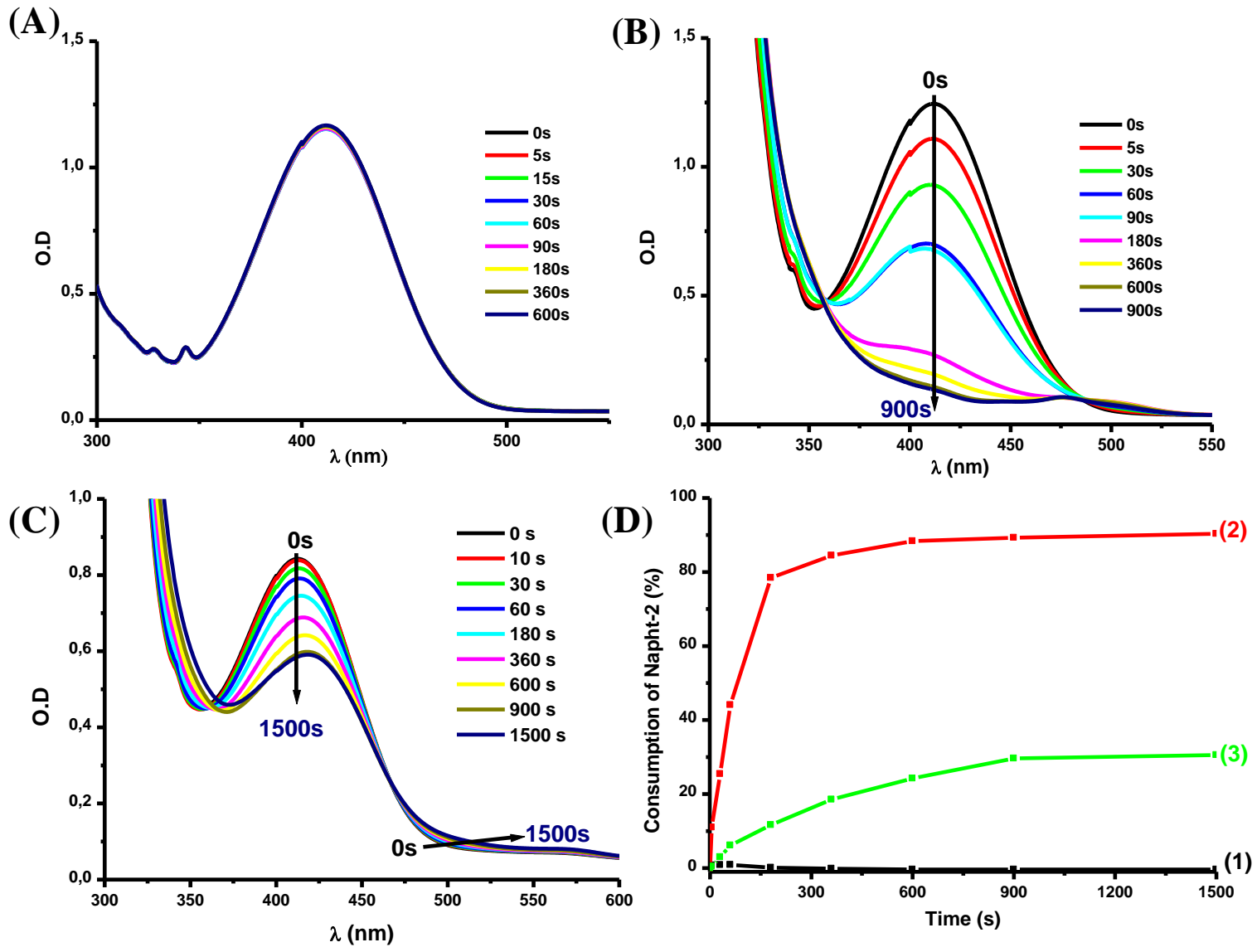

Figure 10. (A) Photolysis of Napht-2 alone in ACN, (B) Photolysis of Napht-2 with Iod $\left(10^{-2} \mathrm{M}\right)$ in ACN, (C) Percentage of consumption of Napht-2 (1) without and with (2) With Iod and (3) With Iod/NPG vs. irradiation time - upon exposure to the LED@375 nm in ACN.

\subsection{Fluorescence quenching and cyclic voltammetry experiments}

Emission and fluorescence quenching spectra of Naphthalimides have been obtained in ACN (e.g Napht-2) and the different curves are reported in Figure 11. First of all, the addition of Iod clearly showed a decrease in the emission intensity of Napht-2. This result confirms those obtained during the photolysis experiments and during the free radical polymerization, suggesting a strong interaction between the excited state of the PI and Iod. From these fluorescence quenching data, Stern-Volmer coefficients could be extracted (e.g. Ksv= $43 \mathrm{M}^{-1}$ 
for Napht-2 and $119 \mathrm{M}^{-1}$ for Napht-3) and rather high electron transfer quantum yields were obtained (Table 5)) according to the equation 2:

$$
\phi_{\mathrm{S} 1}=\mathrm{K}_{\mathrm{SV}}[\operatorname{Iod}] /\left(1+\mathrm{K}_{\mathrm{SV}}[\operatorname{Iod}]\right) \quad \text { eq. } 2
$$

The excited state energy $\left(\mathrm{E}_{\mathrm{S} 1}\right)$ of the Naphthalimide derivatives (determined by the crossing point of the emission and absorption spectra Figure 11D) and the electrochemical properties (oxidation potential) calculated by cyclic voltammetry allowed to determine the free energy change $\Delta \mathrm{G}$ (using eq.1) e.g. $\Delta \mathrm{G}=-1.48 \mathrm{eV}$ for Napht-2 and $-1.44 \mathrm{eV}$ for Napht-3 (Table 5).
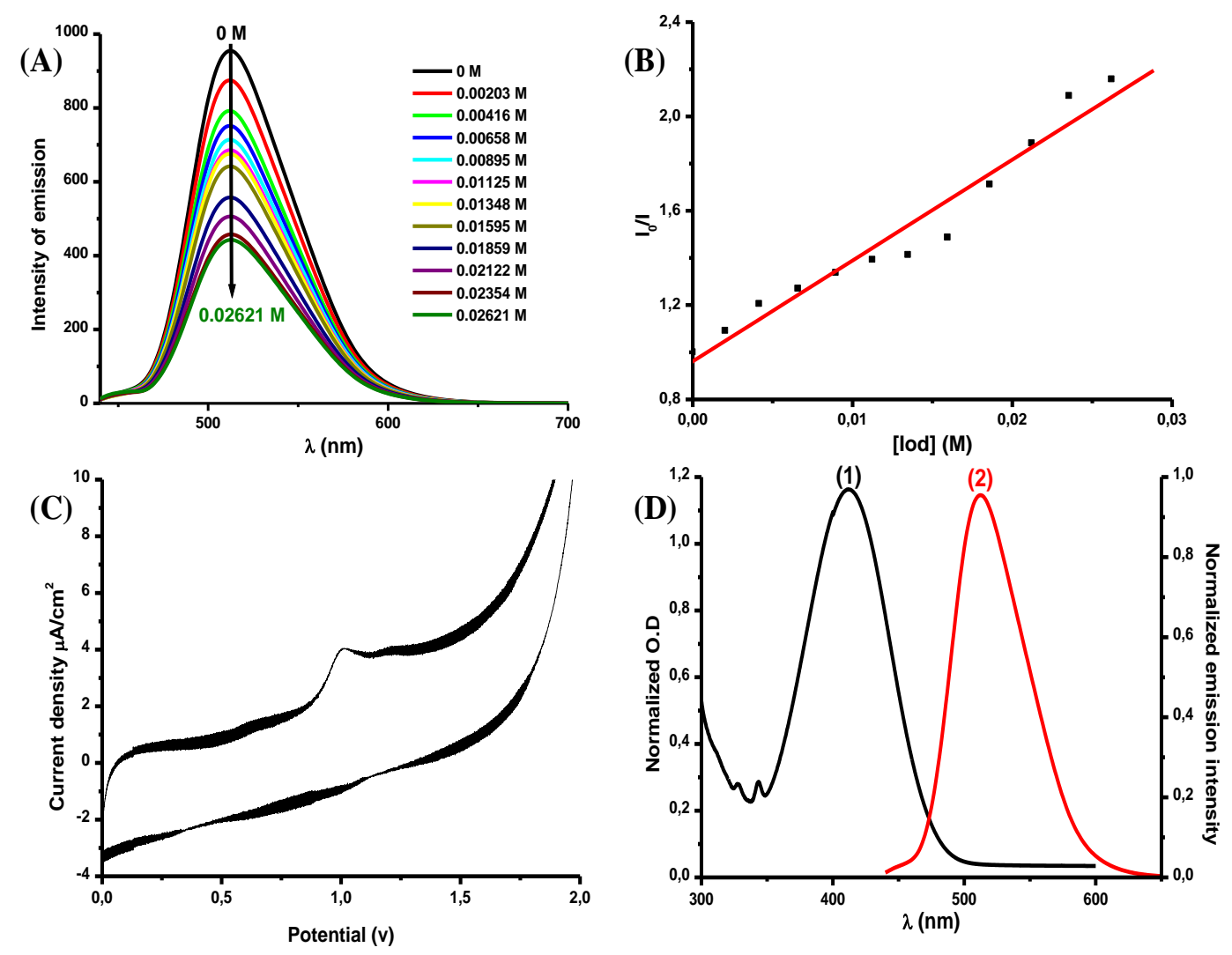

Figure 11. (A) Fluorescence quenching of Napht-2 by Iod, (B) Determiantion of $\mathrm{K}_{\mathrm{SV}}$ (Stern-Volmer coefficient), (C) Oxidation potential (Eox) determination of Napht-2 and (D) $\mathrm{E}_{\mathrm{S} 1}$ determination.

Table 5. Parameters characterizing the chemical mechanisms associated with ${ }^{1} \mathrm{Napht} / \mathrm{Iod}$ interaction in acetonitrile. For Iod, a reduction potential of $-0.2 \mathrm{eV}$ was used for the $\Delta$ Get calculations.

\begin{tabular}{|c|c|c|c|c|c|}
\hline & $\begin{array}{c}\mathbf{E}_{\text {ox }} \\
(\mathbf{v})\end{array}$ & $\begin{array}{c}\mathbf{E}_{\mathrm{S} 1} \\
(\mathbf{e V})\end{array}$ & $\begin{array}{c}\Delta \mathbf{G}_{\mathrm{S} 1} \\
(\mathbf{e V})\end{array}$ & $\begin{array}{c}\mathbf{K}_{\mathrm{SV}} \\
\left(\mathbf{M}^{-1}\right)\end{array}$ & $\begin{array}{c}\Phi_{\text {et }} \\
\text { (Naphtaimide/Iod) }\end{array}$ \\
\hline
\end{tabular}




\begin{tabular}{|c|c|c|c|c|c|}
\hline Napht-1 & 1.02 & 2.63 & -1.41 & 59.9 & 0.54 \\
\hline Napht-2 & 0.92 & 2.61 & -1.48 & 42.8 & 0.46 \\
\hline Napht-3 & 0.95 & 2.59 & -1.44 & 119.3 & 0.70 \\
\hline Napht-4 & 0.72 & 2.91 & -1.99 & 3.25 & 0.06 \\
\hline Napht-5 & 0.97 & 2.57 & -1.4 & 24.8 & 0.33 \\
\hline Napht-6 & 1.00 & 2.57 & -1.37 & 93.4 & 0.65 \\
\hline
\end{tabular}

Based on the different characterization techniques (Photolysis, fluorescence quenching, cyclic voltammetry), the free radical polymerization (FRP) results can be explained by a global chemical mechanism (See Scheme 3). Firstly, the photoinitiator goes to its excited state once it is irradiated by the LED@405nm, so that radicals ( $\mathrm{Ar}^{\bullet}$ and $\mathrm{Napht}^{+}$) are generated by the interaction between PI and Iod (r2). Interaction between the Iod salt and the amine (NPG) lead to the formation of a Charge transfer complex (CTC), which is very sensitive to light, this complex will be, therefore, the source of the formation of radicals $\left(\mathrm{Ar}^{\bullet}\right)$ (r3-r4). In addition, a hydrogen transfer process from the amine to PI can occur which generates two types of radicals $\left(\right.$ Napht- $\mathrm{H}^{\bullet}$ and $\left.\mathrm{NPG}_{(-\mathrm{H})}{ }^{\bullet}\right)(\mathrm{r} 5)$. Then, a decarboxylation of $\mathrm{NPG}_{(-\mathrm{H})} \bullet$ leads to the formation of an intermediate radical $\left(\mathrm{NPG}_{(-\mathrm{H},-\mathrm{CO} 2)^{\bullet}}\right)$ which is capable of producing reactive species $\left(\mathrm{Ar}^{\bullet}\right.$ and $\mathrm{NPG}_{(-\mathrm{H}, \mathrm{CO} 2)}{ }^{+}$) by interaction with Iod (r6-r7). Therefore, $\mathrm{Ar}^{\bullet}$ and $\mathrm{NPG}_{(-\mathrm{H},-\mathrm{CO} 2)}{ }^{\bullet}$ ) (r1-r9) radicals can be considered to be the reactive species in charge of the FRP of the acrylate and methacrylate functions of TMPTA, TA and Mix-MA in two or three-component PISs. For the three-component system, the naphthalimide consumption is reduced (Figure 10C) in agreement with its regeneration in r8-r9 and a partial photoredox catalyst behavior.

Naphthalimide $(\mathrm{h} v) \rightarrow^{1,3}$ Naphthalimide $\quad$ r1

${ }^{1,3}$ Naphthalimide $+\mathrm{ArI}^{+} \rightarrow \mathrm{Ar}^{\bullet}+\mathrm{ArI}+$ Naphthalimide ${ }^{\bullet+} \rightarrow \mathrm{Ar}_{2} \mathrm{I}^{\bullet} \quad \mathrm{r} 2$

$\mathrm{NPG}+\mathrm{Iod} \rightarrow[\text { NPG-Iod }]_{\mathrm{CTC}} \quad \mathrm{r3}$

$[\mathrm{NPG}-\mathrm{Iod}]_{\mathrm{CTC}} \rightarrow \mathrm{Ar}^{\bullet} \quad \mathrm{r} 4$

${ }^{1,3}$ Naphthalimide $+\mathrm{NPG} \rightarrow$ Naphthalimide- $\mathrm{H}^{\bullet}+\mathrm{NPG}_{(-\mathrm{H})} \bullet \quad \mathrm{r} 5$

$\mathrm{NPG}_{(-\mathrm{H})} \bullet \rightarrow \mathrm{NPG}_{(-\mathrm{H} ;-\mathrm{CO} 2)}{ }^{\bullet}+\mathrm{CO}_{2}$

$\mathrm{NPG}_{(-\mathrm{H} ;-\mathrm{CO} 2)}{ }^{\bullet} \mathrm{Ar}_{2} \mathrm{I}^{+} \rightarrow \mathrm{NPG}_{(-\mathrm{H} ;-\mathrm{CO} 2)}{ }^{+}+\mathrm{Ar}^{\bullet}+\mathrm{ArI}$

Naphthalimide $^{\bullet+}+\mathrm{NPG} \rightarrow$ Naphthalimide $+\mathrm{NPG}^{\bullet+} \quad$ r8 
Scheme 3. Expected chemical mechanisms

\section{Conclusion}

In this work, a series of six compounds based on Naphthalimide derivatives have been proposed for the first time as efficient photoinitiators for the free radical polymerization (FRP) of (meth)acrylates functions upon visible light irradiation using LED@405 nm. Interestingly, these naphthalimides have been tested for 3D printing experiments and for the synthesis of photocomposites with significant curing of the surface and the bottom using a LED conveyor @ $395 \mathrm{~nm}$. A new water soluble photoinitiator (Napht-4) has also been proposed in this work. In light of the high efficiency of naphtalimides in FRP under visible light irradiation, future developments will consist in designing Naphthalimides absorbing in the near infrared range, where the light penetration is more important than in the near UV/visible range.

\section{Acknowledgments}

This work was granted access to the HPC resources of the Mesocentre of the University of Strasbourg. 


\section{References:}

[1] J.P. Fouassier, Photoinitiation; photopolymerization; photocuring: Fundamental and Applications, Munich: Hanser, 1995.

[2] J.P. Fouassier, Photochemistry and UV Curing, Research Signpost, Trivandrum, India, 2006.

[3] J.P. Fouassier, Photoinitiator, Photopolymerization and Photocuring: Fundamentals and Applications Gardner Publications: New York, 1995.

[4] J.P. Fouassier, J. Lalevée, Photoinitiators for Polymer Synthesis, Scope, Reactivity, Efficiency; Wiley-VCH Verlag GmbH \& Co.KGaA: Weinheim, Germany, 2012.

[5] K.A. Dietliker, Compilation of Photoinitiators Commercially Available for UV Today, Sita Technology Ltd., London, 2002.

[6] S. Davidson, Exploring the Science, Technology and Application of UV and EB Curing, Sita Technology Ltd., London, 1999.

[7] J.V. Crivello, K. Dietliker, G. Bradley, Photoinitiators for Free Radical Cationic \& Anionic Photopolymerisation, John Wiley \& Sons: Chichester, U. K., 1999.

[8] J.P. Fouassier, J. Lalevee, Photochemistry, 2015, 42, 215- 232.

[9] F. Dumur, D. Gigmes, J.-P. Fouassier, J. Lalevee, Acc. Chem. Res., 2016, 49, 1980-1989.

[10] C. Dietlin, S. Schweizer, P. Xiao, J. Zhang, F. Morlet-Savary, B. Graff, J.-P. Fouassier, J. Lalevee, Polym. Chem., 2015, 6, 3895-3912.

[11] N. Zivic, M. Bouzrati-Zerelli, A. Kermagoret, F. Dumur, J.-P. Fouassier, D. Gigmes, J. Lalevee, ChemCatChem, 2016, 8, 1617-1631.

[12] R.W. Middleton, J. Parrick, E.D. Clarke, P. Wardman, J. Heterocycl. Chem., 1986, 23, 849-855.

[13] D. Jacquemin, E. A. Perpète, G. Scalmani, M. J. Frisch, I. Ciofini, C. Adamo, Chem. Phys. Lett., 2007, 448, 3-6. 
[14] S. Banerjee, E.B. Veale, C.M. Phelan, S.A. Murphy, G.M. Tocci, L.J. Gillespie, D.O. Frimannsson, J.M. Kelly, T. Gunnlaugsson, Chem. Soc. Rev. 2013, 42, 1601-1618.

[15] M.H. Lee, J.Y. Kim, J.H. Han, S. Bhuniya, J.L. Sessler, C. Kang, J.S. Kim, J. Am. Chem. Soc. 2012, 134, 30, 12668-12674.

[16] A-H. Bonardi, S. Zahouily, C. Dietlin, B. Graff, F. Morlet-Savary, M. Ibrahim-Ouali, D. Gigmes, N. Hoffmann, F. Dumur, J. Lalevee, Catalysts, 2019, 9, 637-657.

[17] J. Zhang, N. Zivic, F. Dumur, P. Xiao, B. Graff, JP. Fouassier, D. Gigmes, J. Lalevee, ChemPhotoChem, 2018, 2, 481-489.

[18] P. Xiao, F. Dumur, M. Frigoli, M.-A. Tehfe, D. Gigmes, J.-P. Fouassier, J. Lalevée, Naphthalimide based methacrylated photoinitiators in radical and cationic, Polym. Chem., 2013, 4, 5440-5448.

[19] P. Xiao, F. Dumur, B. Graff, D. Gigmes, J.-P. Fouassier, J. Lalevée, Macromolecules, 2014, 47, 601-608.

[20] J. Zhang, N. Zivic, F. Dumur, P. Xiao, B. Graff, D. Gigmes, J.-P. Fouassier, J. Lalevée, J. Polym. Sci. A Polym. Chem., 2015, 53, 445-451.

[21] P. Xiao, F. Dumur, J. Zhang, B. Graff, D. Gigmes, J.-P. Fouassier, J. Lalevée, J. Polym. Sci. A Polym. Chem., 2015, 53, 665-674.

[22] J. Zhang, F. Dumur, P. Xiao, B. Graff, D. Bardelang, D. Gigmes, J.-P. Fouassier, J. Lalevée, Macromolecules, 2015, 48, 2054-2063

[23] P. Xiao, F. Dumur, J. Zhang, B. Graff, D. Gigmes, J.-P. Fouassier, J. Lalevée, Macromol. Chem. Phys., 2015, 216, 1782-1790.

[24] P. Xiao, F. Dumur, B. Graff, F. Morlet-Savary, J.-P. Fouassier, D. Gigmes, J. Lalevée, J. Polym. Sci. A Polym. Chem., 2015, 53, 2860-2866.

[25] N. Zivic, J. Zhang, D. Bardelang, F. Dumur, P. Xiao, T. Jet, D.-L. Versace, C. Dietlin, F. Morlet-Savary, B. Graff, J.-P. Fouassier, D. Gigmes, J. Lalevée, Polym. Chem., 2016, 7, 418429.

[26] P. Xiao, F. Dumur, J. Zhang, B. Graff, D. Gigmes, J.-P. Fouassier, J. Lalevée, RSC Advances, 2016, 6, 48684-48693.

[27] D. Rehm and A. Weller, Isr. J. Chem., 1970, 8, 259-271. 
[28] J.B. Foresman, A. Frisch, Exploring Chemistry with Electronic Structure Methods, second ed., Gaussian Inc., Pittsburgh, PA, 1996.

[29] M.J. Frisch, G.W. Trucks, H.B. Schlegel, G.E. Scuseria, M.A. Robb, J.R. Cheeseman, V.G. Zakrzewski, J.A. Montgomery, J.R.E. Stratmann, J.C. Burant, S. Dapprich, J.M. Millam, A.D. Daniels, K.N. Kudin, M.C. Strain, O. Farkas, J. Tomasi, V. Barone, M. Cossi, R. Cammi, B. Mennucci, C. Pomelli, C. Adamo, S. Clifford, J. Ochterski, G.A. Petersson, P.Y. Ayala, Q. Cui, K. Morokuma, P. Salvador, J.J. Dannenberg, D.K. Malick, A.D. Rabuck, K. Raghavachari, J.B. Foresman, J. Cioslowski, J.V. Ortiz, A.G. Baboul, B.B. Stefanov, G. Liu, A. Liashenko, P. Piskorz, I. Komaromi, R. Gomperts, R.L. Martin, D.J. Fox, T. Keith, M.A. Al-Laham, C.Y. Peng, A. Nanayakkara, M. Challacombe, P.M.W. Gill, B. Johnson, W. Chen, M. Wong, J.L. Andres, C. Gonzalez, M. Head-Gordon, E.S. Replogle, J.A. Pople, Gaussian 03, Revision B-2, Gaussian Inc., Pittsburgh, PA, 2003.

[30] Composites Market Global Forecast to 2024, MarketsandMarkets, 2019. 
TOC graphic:

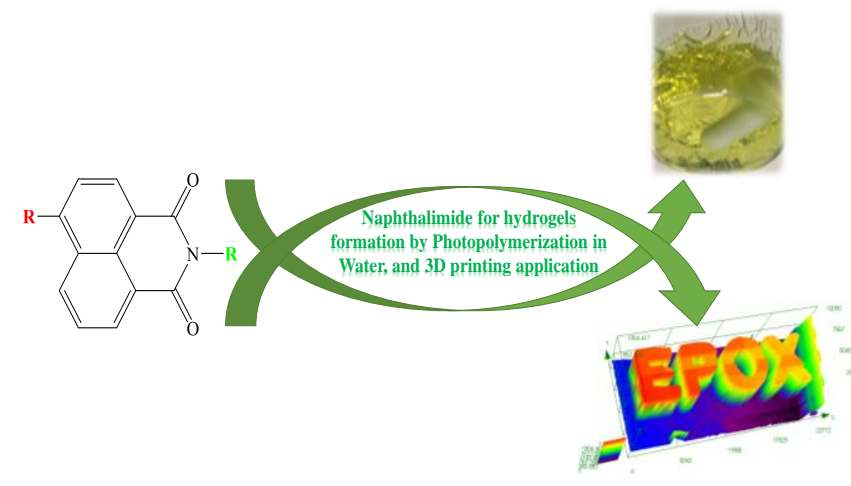

